\title{
Identification of key aerosol populations through their size and composition resolved spectral scattering and absorption
}

\author{
F. Costabile, F. Barnaba, F. Angelini, and G. P. Gobbi \\ Institute for Atmospheric Sciences and Climate, National Research Council (ISAC-CNR), Rome, Italy \\ Correspondence to: F. Costabile (f.costabile@isac.cnr.it)
}

Received: 11 June 2012 - Published in Atmos. Chem. Phys. Discuss.: 17 July 2012

Revised: 15 January 2013 - Accepted: 4 February 2013 - Published: 5 March 2013

\begin{abstract}
Characterizing chemical and physical aerosol properties is important to understand their sources, effects, and feedback mechanisms in the atmosphere. This study proposes a scheme to classify aerosol populations based on their spectral optical properties (absorption and scattering). The scheme is obtained thanks to the outstanding set of information on particle size and composition these properties contain. The spectral variability of the aerosol single scattering albedo (dSSA), and the extinction, scattering and absorption Angstrom exponents (EAE, SAE and AAE, respectively) were observed on the basis of two-year measurements of aerosol optical properties (scattering and absorption coefficients at blue, green and red wavelengths) performed in the suburbs of Rome (Italy). Optical measurements of various aerosol types were coupled to measurements of particle number size distributions and relevant optical properties simulations (Mie theory). These latter allowed the investigation of the role of the particle size and composition in the bulk aerosol properties observed. The combination of simulations and measurements suggested a general "paradigm" built on dSSA, SAE and AAE to optically classify aerosols. The paradigm proved suitable to identify the presence of key aerosol populations, including soot, biomass burning, organics, dust and marine particles. The work highlights that (i) aerosol populations show distinctive combinations of SAE and dSSA times AAE, these variables being linked by a linear inverse relation varying with varying SSA; (ii) fine particles show $\mathrm{EAE}>1.5$, whilst $\mathrm{EAE}<2$ is found for both coarse particles and ultrafine soot-rich aerosols; (iii) fine and coarse particles both show SSA $>0.8$, whilst ultrafine urban Aitken mode and soot particles show SSA $<0.8$. The proposed paradigm agrees with aerosol observations performed during past major field campaigns, this indicating that relations concerning the paradigm have a general validity.
\end{abstract}

\section{Introduction}

Aerosol particles play a central role in the atmosphere. Small variations of their chemical and physical properties generate significant feedback mechanisms, with complex and combined impacts ranging from local air pollution and related health effects (WHO, 2003) to global climate (IPCC, 2007). Variations of their optical properties and capability to act as cloud condensation nuclei (CCN) are determinant for the climatic (direct and indirect, respectively) impact.

Tropospheric aerosols may contain carbonaceous material, sulfate, nitrate, ammonium, trace metals, sea salts, and crustal elements - their sizes spanning over more than four orders of magnitude, from a few nanometers to several micrometers (e.g., Seinfeld and Pandis, 2006). Particle sizes and composition together with their mixing state and shape identify aerosol populations - each of them having specific chemical, optical and physical properties, as well as sources and sinks, space scales and lifetime. Whilst aerosol mass is dominated by the "coarse" (particle diameter, $D_{\mathrm{p}}$ from 1.0 to $10 \mu \mathrm{m})$ and fine $\left(D_{\mathrm{p}}<1.0 \mu \mathrm{m}\right.$, the "accumulation" mode) particles, their number is dominated by the ultrafine particles (UFP, $D_{\mathrm{p}}<100 \mathrm{~nm}$ ) in the "nucleation", and "Aitken" mode $\left(D_{\mathrm{p}}<50 \mathrm{~nm}, 50-100 \mathrm{~nm}\right.$, respectively). The size-resolved understanding of the particle numbers, and in particular of the carbonaceous aerosols, is among the major knowledge gaps to assess the impact of air pollution on climate (Kulmala et al., 2011).

Carbonaceous aerosols include black carbon (BC) and organic material $(\mathrm{OM})$, and represent most of the anthropogenic aerosol in terms of both mass and number concentrations. $\mathrm{BC}$ in the lower atmosphere is the major absorbing component of atmospheric aerosol and a harmful air pollutant that has both substantial regional and 
global climate impacts, and adverse human health effects (UNEP, 2011). Recently, Reche et al. (2011) demonstrated that between 3 and $20 \%$ of $\mathrm{PM}_{10}$ at several European urban sites is due to BC. Conversely, OM has been thought to have a cooling effect (i.e., negligible absorption properties); some organic compounds, however, have been found to absorb light in the UV and visible (Kirchstetter et al., 2004; Andreae and Gelencsér, 2006), and have therefore been referred to as "brown carbon" (Andreae and Gelencsér, 2006; Alexander et al., 2008). The brown carbon, a subset of the whole organic carbon, exhibits a strong wavelength- $(\lambda)$ dependent absorption in the UV and visible, which is larger at near-UV and blue wavelengths (Sun et al., 2007). Jacobson (2001) identified nitrated and aromatic compounds as likely absorbers. Bond (2001) suggested different levels of aromatization to explain the particle absorption spectral variability. So far a complete knowledge of the nature of brown carbon remains indefinite.

The wavelength dependence of the light absorption is crucial to evaluate the spectral single scattering albedo (SSA) (Bergstrom et al., 2007; Russell et al., 2010), a key parameter in the evaluation of the aerosol (direct) climate forcing. Bergstrom et al. (2007) showed that the absorption coefficient decreases monotonically with wavelength and can be approximated by a power law expression, i.e., described by an absorption Angstrom exponent (AAE). The slope of this decrease (or the value of AAE) strongly depends on the aerosol characteristics. Although crucial, it is actually quite difficult to accurately measure the absorption resolved by wavelength, particle size, shape, composition and internal mixing state. In addition, a lack of a generally accepted reference or calibration standard for the aerosol absorption coefficient remains (e.g., Moosmüller et al., 2009). As a consequence, the spectral variability of both light absorption and SSA is still poorly determined and bears a large uncertainty.

In the past much attention has been devoted to the spectral variability of the light scattering and extinction (quantified by the scattering and extinction Angstrom exponents, SAE and EAE). SAE and EAE data have been analyzed by several authors to classify aerosol types in terms of particle size (e.g., O'Neill et al., 2001a,b; Gobbi et al., 2007). Gobbi et al. (2007) proposed a graphical method to gain information on the relevant extinction and the size of the fine aerosols based on the EAE and its spectral curvature. The method, applied to AERONET data (Holben et al., 1998), allowed for easy identification of some aerosol-type fingerprints (e.g., mineral dust, pollution) (Basart et al., 2009). Combination of extinction or scattering (EAE or SAE) and absorption (AAE) spectral variability is becoming more and more used to infer aerosol composition from optical data (e.g., Bergstrom et al., 2007; Clarke et al., 2007; Yang et al., 2009; Gyawali et al., 2012; Lee et al., 2012). Clarke et al. (2007) used the analysis of SAE and AAE to distinguish between dust, biomass burning and urban aerosol in airborne in situ data. Yang et al. (2009) used SAE versus AAE for Beijing, and sepa- rated dust (generally SAE close to zero and AAE variable, but high), fresh plumes (AAE around 1), and coal pollution (more variable AAE because of the formation of brown carbon). Gyawali et al. (2012) clearly separated clean days from polluted days by combining AAE and SAE with SSA.

The spectral variability of SSA $(\mathrm{dSSA} / \mathrm{d} \lambda)$ has been also proposed as an indicator of particle size. Ackerman and Toon (1981) found that positive $\mathrm{dSSA} / \mathrm{d} \lambda$ can be caused by the domination of the coarse particle mode in the aerosol size distribution. Bergstrom (1973) showed that for atmospheric aerosols that do not contain large particles, SSA of the mixture decreases with $\lambda$. Several authors have investigated the dependence of dSSA/d $\lambda$ on aerosol composition. Kaufman et al. (2001) showed that SSA for dust increases with increasing $\lambda$ because of the absorption in the blue channels due to the presence of iron oxides in hematites. Dubovik et al. (2002) obtained dSSA/d $\lambda<0$ for urban pollution and smoke aerosols. Bergstrom et al. (2002) proposed the use of the spectral SSA variability to differentiate between dust and BC absorption. Russell et al. (2010) analyzed SSA and AAE in AERONET and in situ data, and concluded that information on aerosol type cannot come from the wavelength dependence of absorption only, the particle size information in the scattering wavelength dependence being also needed.

In this work we observed the spectral aerosol absorption and scattering properties in the visible region at a suburban Mediterranean site (Rome) together with particle number size distributions. In situ observations were interpreted on the basis of numerical simulations (Mie theory) to investigate intensive optical properties resolved by particle size and refractive index. The objective was to infer a general classification scheme based on the intensive parameters SAE, AAE, SSA and dSSA coupled to the particle size information to "optically" separate key aerosol populations including soot, biomass burning, organic, inorganic, dust and marine aerosols.

\section{Experimental}

In situ aerosol optical properties have been continuously measured at the ISAC Rome Atmospheric Supersite (http: //www.diapason-life.eu/images/RAS-LAST.pdf) since October 2010. The site, representative of suburban background conditions with regular advection of Saharan dust (Barnaba and Gobbi, 2004; Gobbi et al., 2004), is located in the southern outskirts of Rome within $5 \mathrm{~km}$ from the city boundary and $40 \mathrm{~km}$ from the Mediterranean coast. The dataset presented here includes data from October 2010 to March 2012.

An integrating nephelometer (Ecotech, mod.Aurora 3000) was operated to measure the scattering coefficient $\left(\sigma_{\mathrm{s}}\right)$ due to aerosol particles at three wavelengths, $450,520,635 \mathrm{~nm}$. A full calibration of the nephelometer was performed regularly one time per season by using $\mathrm{CO}_{2}$ as span gas. Zero calibration and adjust were performed once a day by using 
internally filtered particle free air. Raw data provided by the nephelometer, $\sigma_{\text {neph }}$, were corrected for truncation according to Anderson and Ogren (1998), Bond (2001), and Müller et al. (2011). Briefly, the true scattering coefficient, $\sigma_{\mathrm{s}}$, is obtained by $\sigma_{\mathrm{s}}=C \cdot \sigma_{\text {neph }}$, with correction factors $C=C(\lambda)$ calculated as $C=a+b \cdot$ SAE. The coefficients $a=a(\lambda)$ and $b=b(\lambda)$ at each wavelength were taken from Müller et al. (2011), with the SAE being calculated starting from the uncorrected nephelometer data $\sigma_{\text {neph }}$. The results showed larger truncation error for larger $\sigma_{\mathrm{s}}$. According to Bond et al. (2009), we estimated a scattering error for truncation of $1-$ $3 \%$.

A 3-wavelength particle soot absorption photometer (PSAP, Radiance Research) was operated to measure the absorption coefficient $\sigma_{\mathrm{p}}$ at three wavelengths, namely 467 , $530,660 \mathrm{~nm}$. Raw PSAP data were corrected after the iterative procedure described by Bond et al. (1999), Virkkula et al. (2005), and Virkkula (2010). The procedure requires wavelength-resolved $\sigma_{\mathrm{s}}$, which were extrapolated from the nephelometer measurements by means of the measured SAE. Since the PSAP correction factors strongly depend on the filter transmittance ( $\mathrm{Tr}$ ), only data with $\mathrm{Tr}>0.7$ are generally used (Bond et al., 1999). However, due to the high aerosol burden at our site the filter gets often loaded in a few hours. We therefore retained PSAP data with $\operatorname{Tr}>0.5$ to increase the data temporal coverage. Overall, the accuracy of the PSAP measurement considering all corrections is estimated on the order of 20-30\% (e.g., Bond et al., 1999; Virkkula et al., 2005; Cappa et al., 2008; Lack et al., 2008). PSAP measurements can be further complicated by the presence of organic species in the liquid state, which can wet the filter material (Subramanian et al., 2007; Lack et al., 2008). In principle, a similar effect can result in the presence of ultrafine liquid particles as well. PSAP data should be therefore considered as an upper limit of the "true" value.

Total particle number concentration $(N)$ was measured by a condensation particle counter, CPC (TSI, mod.3022A). The lowest cut-off particle diameter $\left(D_{\mathrm{p}}\right)$ is $D_{\mathrm{p} 50}(50 \%$ of particle detection) at $7 \mathrm{~nm}$, and $D_{\mathrm{p} 90}$ at $15 \mathrm{~nm}$. The $N_{7}$ (total number concentration of particles larger than $7 \mathrm{~nm}$ ) is up to $10^{6} \mathrm{Acm}^{-3}$.

Even if the accuracy of both PSAP and nephelometer was sufficiently large - after all corrections discussed - we excluded very low values of scattering and absorption coefficients $\left(<10\right.$ and $<1 \mathrm{Mm}^{-1}$, respectively). Outlier values were also excluded (respectively, $>700$ and $>130 \mathrm{Mm}^{-1}$ for scattering and absorption coefficients.

Additional data resources used in this study include particle number size distribution (PNSD) from $14 \mathrm{~nm}$ to $10 \mu \mathrm{m}$. PNSDs from $14 \mathrm{~nm}$ to $600 \mathrm{~nm}$ were measured by a scanning mobility particle sizer, SMPS (TSI, mod.3936) in the same area and analyzed in a previous work (Costabile et al., 2010). PNSDs from 0.3 to $10 \mu \mathrm{m}$ were measured by an optical particle counter, OPC (FAI instruments). Lidar profiles (e.g., Gobbi et al., 2007) and local meteorological parameters were also available and thus used in support of the data interpretation. Both data were used in case of doubtful situations. Lidar data were used to gain some conclusions concerning coarse aerosols, such as to be sure that there was no dust advection in case of low SAE and large soot particle concentrations. Meteorological data were used to interpret some temporal paths, such as influence of rain on intensive aerosol parameters.

In situ measurements were carried out under dry conditions owing to a relative humidity always below $50 \%$ observed in the in situ instruments. Particle losses into the sampling line were calculated according to Hinds (1999), with the sampling inlets removing particles larger than $10 \mu \mathrm{m}$ and the particle penetration efficiency through the line being $>98 \%$ for $D_{\mathrm{p}}>10 \mathrm{~nm}$.

\section{Results}

An aerosol population can be considered as a set of particles being "homogeneous" with respect to their sizes and composition (and shape and mixing state). The variation of this "homogeneity" translates into a different spectral variation of aerosol scattering and absorption, SAE (or EAE) and AAE varying with varying particle size and composition. In this work our aim is to find proper combination of the intensive parameters SAE, AAE, SSA and dSSA by which key aerosol populations can be optically separated. Similar classifications have been proposed before (cf. Introduction section). Some of those classifications (e.g., Russell et al., 2010) were based on AAE vs. EAE plots. The advantage of using EAE is that it takes contemporarily into account SAE and AAE; however, this is also a disadvantage as EAE fails in separating particle size effects (mainly linked to SAE) from particle composition effects (mainly linked to AAE). To make this separation more evident (i.e., to separate particle size from particle composition effects on the spectral variables) SAE was used instead of EAE.

The SAE vs. AAE relation was first experimentally analyzed in Sect. 3.1. Since SAE represents the scattering spectral variation, and AAE represents the absorption spectral variation, one might expect their combination to correlate to the SSA spectral variation (SSA being a mathematical combination of scattering and absorption). To investigate the way SAE and AAE shall correlate to dSSA (the SSA spectral variation) we combined the relevant experimental data and found significant inverse correlation between SAE and dSSA, and between SAE and dSSA.AAE. Those behaviors observed on experimental data were reproduced by numerical simulations (Sect. 3.2), thus providing theoretical support to the observations. A classification scheme (hereafter referred to as "paradigm") resulted. The relevance of the paradigm is discussed in the Discussion Sect. 4.1, based on both experimental results and numerical simulations. 
Table 1. Acronyms.

\begin{tabular}{|c|c|c|}
\hline Symbol & Meaning & Description \\
\hline AAE & Absorption Angstrom exponent & \\
\hline AKM & Aitken mode & $\begin{array}{l}\text { Urban Aitken mode particles generated by } \\
\text { growing of nucleation mode particles } \\
\text { (AKM might include some condensation } \\
\text { mode particles). }\end{array}$ \\
\hline $\mathrm{BBM}$ & Biomass burning smoke mode & $\begin{array}{l}\text { Small accumulation mode particles rich in } \mathrm{BC} \\
\text { from biomass smoke. }\end{array}$ \\
\hline $\mathrm{BC}$ & Black carbon & \\
\hline CDM & Coarse dust mode & Coarse mode dust particles. \\
\hline dSSA & $\mathrm{dSSA}_{660-467}$ & $\mathrm{SSA}_{660}-\mathrm{SSA}_{467}$ \\
\hline EAE & Extinction Angstrom Exponent & \\
\hline LIM & Large inorganic mode & $\begin{array}{l}\text { Large accumulation mode particles rich in } \\
\text { inorganic matter (e.g., sulphates, sea salts). }\end{array}$ \\
\hline LOM & Large organic mode & $\begin{array}{l}\text { Large accumulation mode particles rich in } \\
\text { light absorbing OM. }\end{array}$ \\
\hline CMM & Coarse marine mode & $\begin{array}{l}\text { Coarse mode particles in the marine aerosol } \\
\text { rich in sea salt and light absorbing OM. }\end{array}$ \\
\hline$N$ & Total particle number & \\
\hline $\mathrm{OM}$ & Organic material & \\
\hline SAE & Scattering Angstrom exponent & \\
\hline STM & Soot mode & $\begin{array}{l}\text { Soot mode particles generated as combustion } \\
\text { by-products consisting of both } \mathrm{BC} \text { and } \mathrm{OM} \text {. }\end{array}$ \\
\hline SOM & Small organic mode & $\begin{array}{l}\text { Condensation mode particles rich in light absorbing OM } \\
\text { (SOM might include both urban and biomass } \\
\text { burning aerosol particles). }\end{array}$ \\
\hline SSA & Single scattering albedo & \\
\hline
\end{tabular}

\subsection{Experimental results}

The spectral optical properties of aerosols were studied through the in situ observation of their scattering $\left(\sigma_{\mathrm{s}}\right)$ and absorption coefficients $\left(\sigma_{\mathrm{p}}\right)$ at three wavelengths in the visible range at the Rome Tor Vergata site. Daily average $\sigma_{\mathrm{s}}$ varied from 30 to $300 \mathrm{Mm}^{-1}$, and $\sigma_{\mathrm{p}}$ from 2 to $50 \mathrm{Mm}^{-1}$ (single measurement reaching up to $800 \mathrm{Mm}^{-1}$, and $100 \mathrm{Mm}^{-1}$, respectively). From these, scattering Angstrom exponent (SAE467-660), absorption Angstrom exponent (AAE 467-660), and single scattering albedo ( $\mathrm{SSA}_{467}, \mathrm{SSA}_{530}$ and $\mathrm{SSA}_{660}$ ) were derived (acronyms are summarized in Table 1). The analysis revealed some relations linking the $\mathrm{SAE}_{467-660}$, the $\mathrm{AAE}_{467-660}$, and the spectral variability of the SSA, i.e., $\mathrm{dSSA}_{660-467}=\mathrm{SSA}_{660}-\mathrm{SSA}_{467}$.

By analyzing the $\mathrm{SAE}_{467-660}$ vs. $\mathrm{AAE}_{467-660}$ experimental data we found inverse correlations between $\mathrm{SAE}_{467-660}$ and $\mathrm{dSSA}_{660-467}=\mathrm{SSA}_{660}-\mathrm{SSA}_{467}$, i.e., the spectral variability of the SSA. Figure 1 shows the observed data (more than 15500 data points) as either EAE (y-axis, upper panels) or SAE (y-axis, lower panels) versus either AAE, dSSA, and dSSA.AAE (x-axis). As previously discussed, SAE vs. dSSA.AAE data $\left(R^{2}=-0.66\right)$ correlate more than SAE vs. AAE data $\left(R^{2}=-0.07\right)$. As well, SAE vs. dSSA.AAE (lower panels, $R^{2}=-0.66$ ) correlate better than EAE vs.
dSSA.AAE (upper panels, $R^{2}=-0.58$ ). Data are color coded by $\mathrm{SSA}_{530}$. Since $\mathrm{AAE}_{467-660}$ is always positive in the visible region (e.g Moosmüller et al., 2011), negative xvalues correspond to negative $\mathrm{dSSA}_{660-467}$. This visualization highlights an inverse linear relation between $\mathrm{SAE}_{467-660}$ and dSSA $660-467 \cdot \mathrm{AAE}_{467-660}$.

Figure 2 shows the same data clustered by the $\mathrm{AAE}_{467-660}$ (left column, panels a-e), and a subset of them color coded by $N_{7}$ (right column, panels $\mathrm{f}-1$ ), when $N_{7}$ data were available. In particular, five separate subsets of the whole dataset are shown (figure rows): $\mathrm{SSA}_{530}>0.95$ (a, f), $0.9<\mathrm{SSA}_{530}<0.95(\mathrm{~b}, \mathrm{~g}), 0.8<\mathrm{SSA}_{530}<0.9$ (c, h), $0.7<\mathrm{SSA}_{530}<0.8$ (d, i), $0.6<\mathrm{SSA}_{530}<0.7$ (e, l). The $\mathrm{AAE}_{467-660}$ color-coded visualization (left column) highlights a strong correlation between the variables. The correlation coefficient $\left(R^{2}\right)$ varies from 0.72 to 0.9 . In general, the lower the $\mathrm{AAE}_{467-660}$ and $\mathrm{SSA}_{530}$, the larger the $R^{2}$.

Figure 2f-1 (right column) shows that low SSA are mainly associated with large particle numbers, and vice versa. In urban areas this is expected, as high $N_{7}$ and low SSA are generally associated with polluted conditions, while clean conditions generally show low $N_{7}$ and high SSA. ( SSA $_{530}>0.95$ (Fig. 2f) are dominated by $N_{7}<$ $10000 \# \mathrm{~cm}^{-3}, \mathrm{AAE}_{467-660}>2$ and $\mathrm{SAE}_{467-660}<2$. Conversely, $\mathrm{SSA}_{530}<0.8$ (Fig. 2i, l) are dominated by $N_{15}>$ 


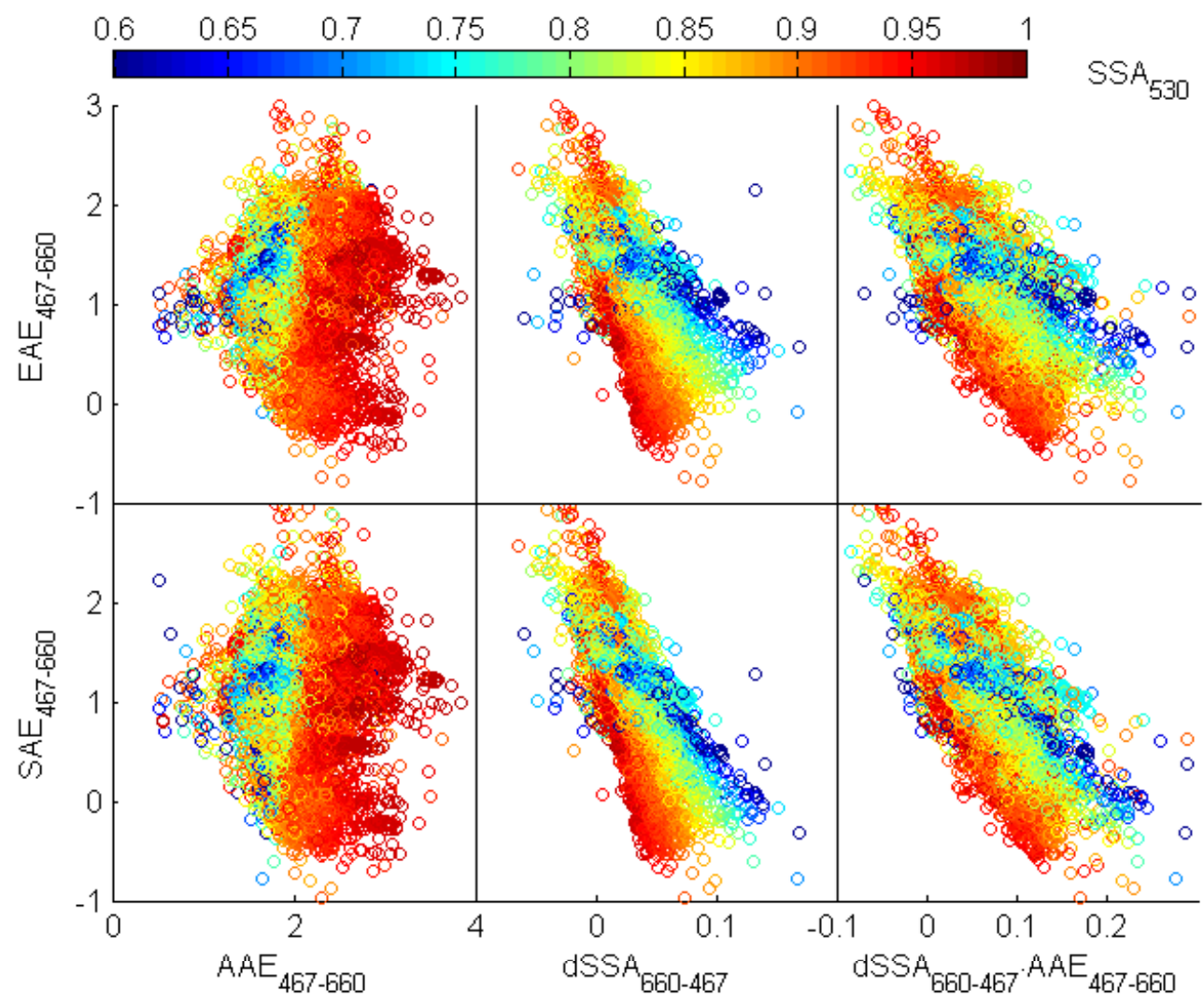

Fig. 1. Inverse linear relation observed between EAE and SAE (y-axis) and AAE, dSSA, and dSSA - AAE (x-axis). The slope varies with varying SSA (color code). Note that since AAE $467-660$ is always positive in the visible region (e.g., Moosmüller et al., 2011), negative $\mathrm{x}$-values correspond to negative $\mathrm{dSSA}_{660-467}$.

$30000 \mathrm{\# cm}^{-3}$.) Note that the largest $N_{7}$ (red dots in Fig. $2 \mathrm{~h}$, i) are not associated with any $\mathrm{SAE}_{467-660}>2$ (Fig. $2 \mathrm{~g}$, h) - a threshold that is conversely used to identify the optical dominance of fine particles. (In fact, $N_{7}>30000 \# \mathrm{~cm}^{-3}$ with $\mathrm{SSA}_{530}<0.7$ (Fig. 21) has $\mathrm{SAE}_{467-660}<1.8$ and $\mathrm{AAE}_{467-660}<2$, whilst $N_{7}>60000 \# \mathrm{~cm}^{-3}$ (Fig. 2i) and $0.7<\mathrm{SSA}_{530}<0.8$ has $\mathrm{SAE}_{467-660}<2$ and $\mathrm{AAE}_{467-660}<$ 2 (but $\mathrm{AAE}_{467-660}>2$ also).) These findings will be further discussed later in view of the simulation outcomes.

\subsection{Numerical simulations}

Numerical simulations of aerosol optical properties were performed to understand and interpret the experimental results presented in the previous section. To this purpose we assumed the observed bulk aerosol properties (Fig. 1) to be the result of a combined effect of different aerosol populations, with each of these dominating a specific particle size range and there described by a typical PNSD and a chemical composition (i.e., by a particle refractive index, $m\left(\lambda, D_{\mathrm{p}}\right)$ ). The primary scope of this exercise was to evaluate the way each aerosol population affects the spectral variability of the bulk aerosol optical properties observed. Mie simulations of the aerosol scattering and absorption coefficients at three wave- lengths $(467,530,660 \mathrm{~nm})$ were then performed, which required definition of a wavelength and size-dependent refractive index $m\left(\lambda, D_{\mathrm{p}}\right)=m_{\operatorname{Re}}\left(\lambda, D_{\mathrm{p}}\right)-m_{\operatorname{Im}}\left(\lambda, D_{\mathrm{p}}\right)$.

Eight different aerosol populations were considered. Each of them covers a specific portion $(60-120 \mathrm{~nm}, 120-300 \mathrm{~nm}$, $300-800 \mathrm{~nm},>800 \mathrm{~nm})$ of the whole $D_{\mathrm{p}}$ size range considered ( $D_{\mathrm{p}}$ from $20 \mathrm{~nm}$ to $\left.10 \mu \mathrm{m}\right)$. Two different sets of $m\left(\lambda, D_{\mathrm{p}}\right)$ were used: they are intended to reproduce two extreme cases of low and high absorbtion, respectively. The average PNSDs used for the simulation were analyzed in a previous work (see Fig. 2 of Costabile et al., 2010), the daily average $N_{7}$ being from 3000 to $30000 \mathrm{\# cm}^{-3}$. The thresholds of the four $D_{\mathrm{p}}$ size regions were identified according to numerous previous studies on urban aerosol PNSD modes (e.g., Costabile et al., 2009, and references therein). Overall, we used approximately 8300 PNSDs.

The eight different populations are summarized in the Table 2 . In the $D_{\mathrm{p}}$ size range $60-120 \mathrm{~nm}$ we defined an "urban Aitken mode" (AKM) and a "soot mode" (STM) using two sets of refractive indices to simulate slightly to highly absorbing particles. In the small accumulation mode size range $\left(D_{\mathrm{p}}=120-300 \mathrm{~nm}\right)$ we included a light absorbing organic mode, i.e., the "small OM condensation mode" (SOM), and 


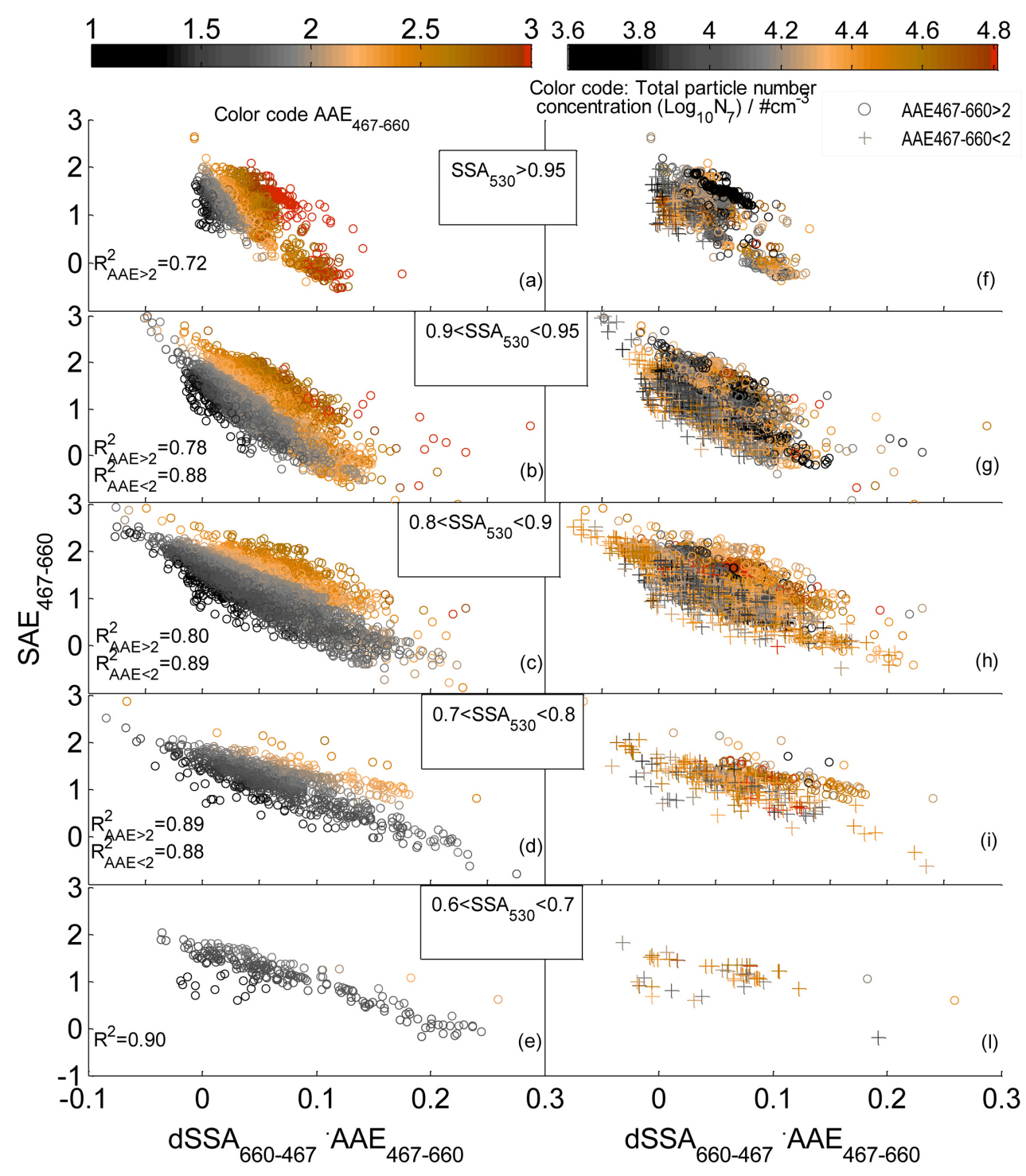

Fig. 2. As in Fig. 1, but data separated in terms of: (i) SSA (by row, same SSA in $\mathbf{a} / \mathbf{f}, \mathbf{b} / \mathbf{g}, \mathbf{c} / \mathbf{h}, \mathbf{d} / \mathbf{i}$, e/l), (ii) AAE (color code of the left column, a, b, c, d, e), and (iii) total particle number concentration, $N$ (color code of the right column, $\mathbf{f}, \mathbf{g}, \mathbf{h}, \mathbf{i}, \mathbf{l}$ ). $R^{2}=$ correlation coefficients between SAE and dSSA AAE separately showed for AAE $<2$ and AAE $>2$. Note that $R^{2}$ varies with varying SSA and AAE.

a "biomass burning mode" (BBM). In the large accumulation mode range $\left(D_{\mathrm{p}}=300-800 \mathrm{~nm}\right)$ we included conditions ranging from an inorganic aerosol mode (inorganic matter, IM, e.g., sulfates in the droplet mode) referred to as " large IM accumulation mode" (LIM), and a light-absorbing organic aerosol mode, i.e., the "large OM accumulation mode" $(\mathrm{LOM})$. Finally, in the coarse mode range $\left(D_{\mathrm{p}}=0.8-10 \mu \mathrm{m}\right)$, we simulated a "coarse marine mode", CMM (sea salts and $\mathrm{OM})$ and a "coarse dust mode" (CDM).

Refractive indices $m\left(\lambda, D_{\mathrm{p}}\right)$ were based on previous similar works (e.g., Kaufman et al., 2001; Dubovik et al., 2002; Bond and Bergstrom, 2006; Alexander et al., 2008; Moosmüller et al., 2009; Flowers et al., 2010; Cai et al.,
$2011)$. The choice of the spectrally dependent $m\left(\lambda, D_{\mathrm{p}}\right)$ to employ was a challenging task due to still limited information available in the literature. Difficulties occurred in finding suitable $m_{\operatorname{Re}}\left(\lambda, D_{\mathrm{p}}\right)$ and $m_{\operatorname{Im}}\left(\lambda, D_{\mathrm{p}}\right)$ for all aerosol populations in Table 2: some of them (e.g., AKM) have never been given a $m\left(\lambda, D_{\mathrm{p}}\right)$, and some of them (e.g., CDM) have been given several values in the literature. We therefore decided to fix a central value $\bar{m}\left(\lambda, D_{\mathrm{p}}\right)$ and a range $\delta m\left(\lambda, D_{\mathrm{p}}\right)$ in which we randomly varied $\bar{m}\left(\lambda, D_{\mathrm{p}}\right)$. We then performed a sensitivity analysis of the calculated variables on the $m\left(\lambda, D_{\mathrm{p}}\right)=\bar{m}\left(\lambda, D_{\mathrm{p}}\right) \pm \delta m\left(\lambda, D_{\mathrm{p}}\right)$. Calculations were carried out in which both the real $m_{\operatorname{Re}}\left(\lambda, D_{\mathrm{p}}\right)$ and the imaginary $m_{\operatorname{Im}}\left(\lambda, D_{\mathrm{p}}\right)$ part of the complex $m\left(\lambda, D_{\mathrm{p}}\right)$ 
Table 2. Aerosol populations (A.P.) used for the numerical simulations. Particle size ranges $\left(D_{\mathrm{p}}\right)$, and refractive index $\left(m\left(\lambda, D_{\mathrm{p}}\right)=\right.$ $\left.m_{\operatorname{Re}}\left(\lambda, D_{\mathrm{p}}\right)-m_{\operatorname{Im}}\left(\lambda, D_{\mathrm{p}}\right)\right)$ are indicated. For the sensitivity analysis $m=\left(\overline{m_{\mathrm{Re}}} \pm \delta m_{\mathrm{Re}}\right)-\left(\overline{m_{\mathrm{Im}}} \pm \delta m_{\mathrm{Im}}\right)$, with $\delta m$ being the range of random variation around the central value $\bar{m}$.

\begin{tabular}{lrrrrrr}
\hline \multirow{2}{*}{ A.P. } & $D_{\mathrm{p}}$ & \multicolumn{2}{c}{$\bar{m}\left(\lambda, D_{\mathrm{p}}\right)=\overline{m_{\mathrm{Re}}}\left(\lambda, D_{\mathrm{p}}\right)-\overline{m_{\mathrm{Im}}}\left(\lambda, D_{\mathrm{p}}\right)$} & \multirow{2}{*}{$\delta m_{\mathrm{Re}}$} & \multirow{2}{*}{$\delta m_{\operatorname{Im}}$} \\
\cline { 3 - 5 } & $(\mathrm{nm})$ & $\lambda=467 \mathrm{~nm}$ & $\lambda=530 \mathrm{~nm}$ & $\lambda=660 \mathrm{~nm}$ & & \\
\hline AKM & $60-120$ & $1.426-0.008 i$ & $1.424-0.005 i$ & $1.425-0.006 i$ & \pm 0.01 & \pm 0.001 \\
STM & $60-120$ & $1.520-0.047 i$ & $1.520-0.047 i$ & $1.520-0.047 i$ & \pm 0.01 & \pm 0.001 \\
SOM & $120-300$ & $1.5-0.02 i$ & $1.486-0.011 i$ & $1.496-0.012 i$ & \pm 0.01 & \pm 0.001 \\
BBM & $120-300$ & $1.512-0.027 i$ & $1.510-0.021 i$ & $1.511-0.022 i$ & \pm 0.01 & \pm 0.001 \\
LIM & $300-800$ & $1.43-0.00002 i$ & $1.43-0.00001 i$ & $1.429-0.000013 i$ & \pm 0.01 & \pm 0.0001 \\
LOM & $300-800$ & $1.460-0.012 i$ & $1.454-0.008 i$ & $1.512-0.0075 i$ & \pm 0.01 & \pm 0.001 \\
CMM & $>800$ & $1.550-0.00019 i$ & $1.550-0.00006 i$ & $1.550-0.00011 i$ & \pm 0.01 & \pm 0.0001 \\
CDM & $>800$ & $1.560-0.008 i$ & $1.550-0.004 i$ & $1.560-0.005 i$ & \pm 0.01 & \pm 0.001 \\
\hline
\end{tabular}

were randomly varied between the extremes of $\bar{m}\left(\lambda, D_{\mathrm{p}}\right) \pm$ $\delta m\left(\lambda, D_{\mathrm{p}}\right)$, namely $m_{\mathrm{Re}}=\bar{m}_{R e} \pm \delta m_{\mathrm{Re}}$ and $m_{\mathrm{Im}}=\bar{m}_{\mathrm{Im}} \pm$ $\delta m_{\mathrm{Im}}$, as shown in Table 2 .

The simulated spectrally dependent aerosol scattering and absorption coefficients were combined to obtain, for every population, the $\mathrm{EAE}_{467-660}, \mathrm{SAE}_{467-660}$, $\mathrm{AAE}_{467-660}$, $\mathrm{SSA}_{467,530,660}$ and $\mathrm{dSSA}_{660-467}$ parameters used in this study. These are shown as a function of the $D_{\mathrm{p}}$ in Fig. 3. Calculations were carried out by using $\bar{m}\left(\lambda, D_{\mathrm{p}}\right)=$ $\overline{m_{\mathrm{Re}}}\left(\lambda, D_{\mathrm{p}}\right)-\overline{m_{\mathrm{Im}}}\left(\lambda, D_{\mathrm{p}}\right)$. Note that the discontinuity of the parameters in the four $D_{\mathrm{p}}$ regions selected is precisely the effect of the assumed type-dependent $m\left(\lambda, D_{\mathrm{p}}\right)$. The effect of the $m\left(\lambda, D_{\mathrm{p}}\right)$ variability within the same $D_{\mathrm{p}}$ size range (i.e., low- and high-absorbtion capabilities in the same $D_{\mathrm{p}}$ range, which means for example CDM and CMM) is conversely shown by the two thin lines, the solid one representing the average of the two.

As expected, the simulated $\mathrm{SAE}_{467-660}$ - and EAE (Fig. 3a) is generally low $(<1)$ for aerosol dominated by the coarse particles, and large $(>1)$ for aerosol dominated by the fine (i.e., the small accumulation mode) particles. However, it is worth noting that a decreasing EAE $467-660$ with decreasing size is obtained in the Aitken mode range, reaching values similar to those typically attributed to coarse mode particles. This behavior is shown to be valid for both AKM and STM populations. This aspect will be discussed in the following.

The simulated AAE $467-660$ (Fig. 3b) shows a strong variability with both particle size and refractive index. AAE $_{467-660}<2$ is mainly associated with STM, whilst $\mathrm{AAE}_{467-660}>2.5$ are found for the SOM, which was intended to simulate the dominance of brown carbon. The BBM simulation shows that $\mathrm{AAE}_{467-660}$ increases with size.

The simulated SSA (Fig. 3c) is large $(>0.9)$ and almost constant in the large accumulation mode, and decreases with both increasing (coarse mode) and decreasing (small accumulation and Aitken mode) diameters. The lowest SSA occurs for the blue and green wavelengths. Note that the lowest SSA $(<0.5)$ is in the Aitken mode size range, where the spectral variability of SSA (in the blue and green) is the largest one. SSA660 shows a comparatively smaller decrease.

Coupling the results of $\mathrm{AAE}_{467-660}$ and dSSA, their product dSSA $660-467 \cdot$ AAE $_{467-660}$ (shown by the light-blue line in Fig. 3d together with dSSA $_{660-467}$ in black) is low in the accumulation mode and large in the coarse and Aitken mode size range, the latter case reaching the largest (absolute) values. This behavior is thus opposite to that of EAE and $\mathrm{SAE}_{467-660}$, and theoretically confirms the inverse relation experimentally observed between $\mathrm{SAE}_{467-660}$ and $\mathrm{dSSA}_{660-467} \cdot \mathrm{AAE}_{467-660}$ (Fig. 1). Negative dSSA $660-467$. AAE $467-660$ mainly result for the smaller diameters (120$250 \mathrm{~nm})$ of BBM and the larger diameters $(90-120 \mathrm{~nm})$ of the Aitken mode. That is to say, $\mathrm{dSSA}_{660-467}<0$ is expected to be associated with aerosols dominated by either accumulation mode BC-rich combustion particles (for simplicity here referred to as BBM), or aged (some hours) urban particles (here referred to as AKM and STM in the 90-120 nm size range).

\section{Discussion}

\subsection{A "paradigm" describing optical properties of aerosol populations}

By combining the experimental results (Fig. 2) and the numerical simulations (Fig. 3) it is possible to explain the effects of key aerosol populations on the bulk intensive optical properties.

Reasons for the clearer separation provided by the proposed paradigm with respect to previous classifications are detailed as follows. First, the inverse correlation between SAE and dSSA resulting from their common dependence on particle size. Second, the inverse correlation between AAE and dSSA resulting from their common dependence on particle composition. Third, the dependence of SSA on particle size in addition to particle composition, which translates into an SSA decreasing for ultrafine particles regardless of their 

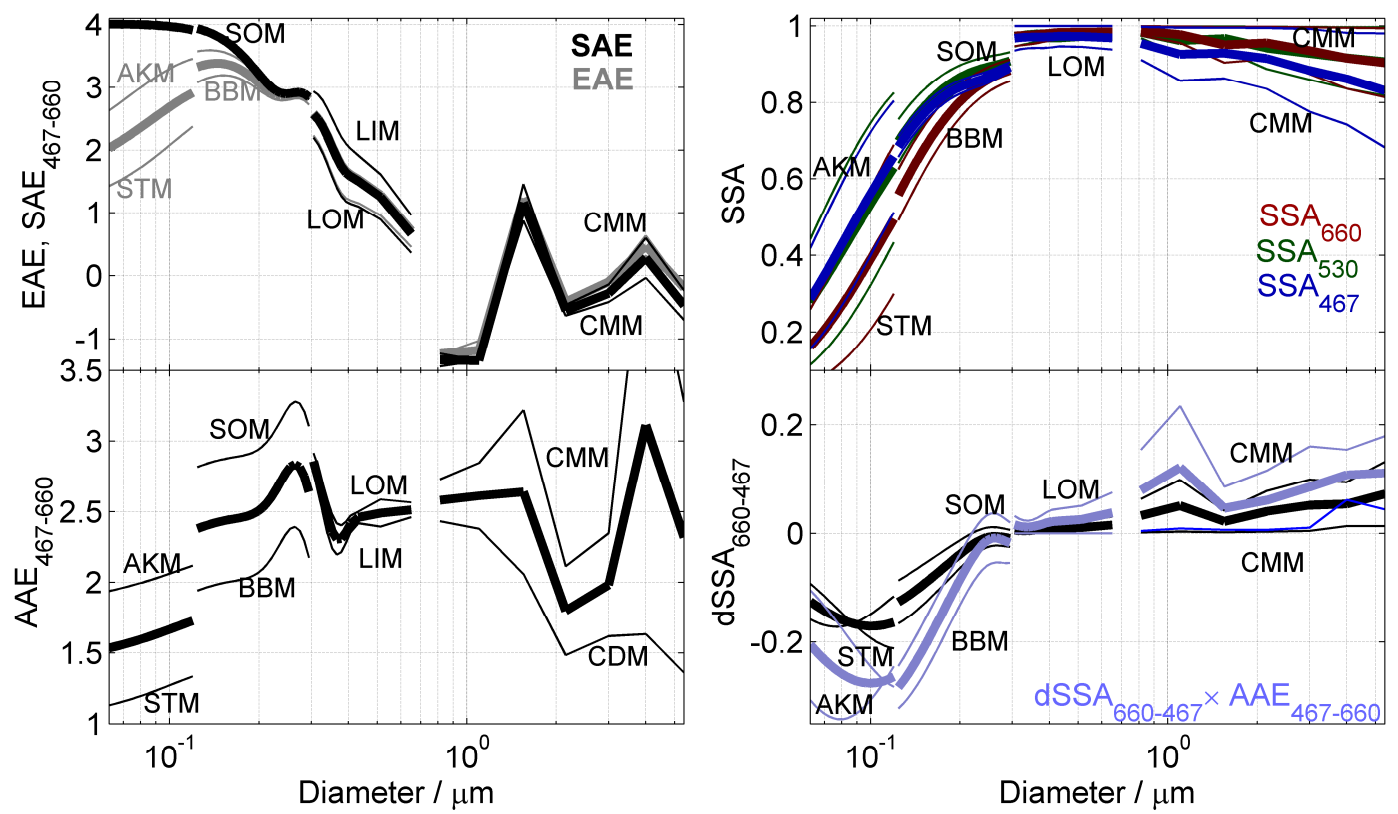

Fig. 3. Numerical simulations (Mie theory) of intensive optical properties: (a) EAE and SAE, (b) AAE, (c) SSA (at blue, green, and red wavelengths), (d) dSSA (black line), and dSSA · AAE (cyan line). Variables are numerically resolved by particle diameter $D_{\mathrm{p}}$ (x-axis) and refractive index $\bar{m}\left(\lambda, D_{\mathrm{p}}\right)$. Light lines represent the $\bar{m}\left(\lambda, D_{\mathrm{p}}\right)$ variability between two extremes whose average value is showed by the thick lines. Note that the variables identify eight aerosol populations indicated by their acronyms (Table 1).

composition (in the ultrafine particle size range, scattering decreases faster than absorption with decreasing particle diameter). Then, the dependence of SAE on particle composition in addition to particle size. Lastly, the fact that separating SAE from AAE (instead of combining them in EAE) helps in separating particle size from particle composition effects.

This is shown in Fig. 4, where the $\mathrm{SAE}_{467-660}$ vs. $\mathrm{dSSA}_{660-467} \cdot \mathrm{AAE}_{467-660}$ relation, as obtained from the numerical simulations, is separately plotted for all identified aerosol population. (Figure S1 in the Supplement is same as Fig. 4 but for the fact that it also shows relations between SAE (y-axis) and either AAE or dSSA (x-axis).) The intensive parameters of the eight aerosol populations in Table 2 were calculated by (i) integrating - for both cases of larger and lower $m_{\operatorname{Im}}\left(\lambda, D_{\mathrm{p}}\right)-$ the relevant extensive optical properties $\sigma_{\mathrm{s}}\left(\lambda, D_{\mathrm{p}}, N_{D_{\mathrm{p}}}\right)$ and $\sigma_{\mathrm{p}}\left(\lambda, D_{\mathrm{p}}, N_{D_{\mathrm{p}}}\right)$ over the four particle size ranges selected $\left(\Delta D_{\mathrm{p}}\right)$, and (ii) then calculating at the selected wavelengths $\Delta \lambda$ the intensive optical parameters $\operatorname{SAE}\left(m, \Delta \lambda, \Delta D_{\mathrm{p}}\right)$, $\operatorname{AAE}\left(m, \Delta \lambda, \Delta D_{\mathrm{p}}\right)$ and $\operatorname{dSSA}\left(m, \Delta \lambda, \Delta D_{\mathrm{p}}\right)$. To assess the robustness of the paradigm we show in Fig. 4 both the calculations in which the central value $\bar{m}\left(\lambda, D_{\mathrm{p}}\right)=$ $\overline{m_{\mathrm{Re}}}\left(\lambda, D_{\mathrm{p}}\right)-\overline{m_{\mathrm{Im}}}\left(\lambda, D_{\mathrm{p}}\right)$ is used (large circles), and the calculations in which the $m\left(\lambda, D_{\mathrm{p}}\right)=\left(\overline{m_{\operatorname{Re}}}\left(\lambda, D_{\mathrm{p}}\right) \pm\right.$ $\left.\delta m_{\operatorname{Re}}\left(\lambda, D_{\mathrm{p}}\right)\right)-\left(\overline{m_{\operatorname{Im}}}\left(\lambda, D_{\mathrm{p}}\right) \pm \delta m_{\operatorname{Im}}\left(\lambda, D_{\mathrm{p}}\right)\right)$ is used (small dots) (cf. Sect. 3.2). More than 140000 cases were calculated and their data points are shown in Fig. 4.
The resulting graph mirrors the experimentally observed graph in Fig. 1. To better represent experimental data, we added in Fig. 4 a mixed aerosol type (the oblique elongated blue set) intended to represent a soot mode dominated aerosol mixed with coarse mode particles (regardless the coarse mode absorption properties). (It was calculated by summing up STM and either CMM or CDM in Table 4.)

The variables this "paradigm" is built on come out by the experimental data analysis (Sect. 3.1), their relevant relations being theorized by the numerical simulations (Sect. 3.2). Numerical results (Fig. 3) both confirmed the inverse relation experimentally found between SAE and dSSA (Fig. 1) and explained its variation with particle size and composition. dSSA is high (absolute value) for large absorbing particles (CDM) as well as for small absorbing particles (STM), both of them (STM and CDM) having low EAE. Contrarily, dSSA approaches zero for accumulation mode particles for which SAE is large. This finding fits in previous studies on dSSA, which (being a sort of SSA Angstrom exponent) has been shown to depend on both particle size and composition (Bergstrom, 1973; Ackerman and Toon, 1981; Kaufman et al., 2001; Dubovik et al., 2002; Bergstrom et al., 2002; Russell et al., 2010) (cf. Sect. 1). In addition, simulation results (Fig. 3) evidence that ultrafine particles can be identified by low SSA - thus regardless of their absorption properties (i.e., AKM in addition to STM). The SSA information added (as color) in the plot thus enhances the identification of both black carbon and UFPs. 


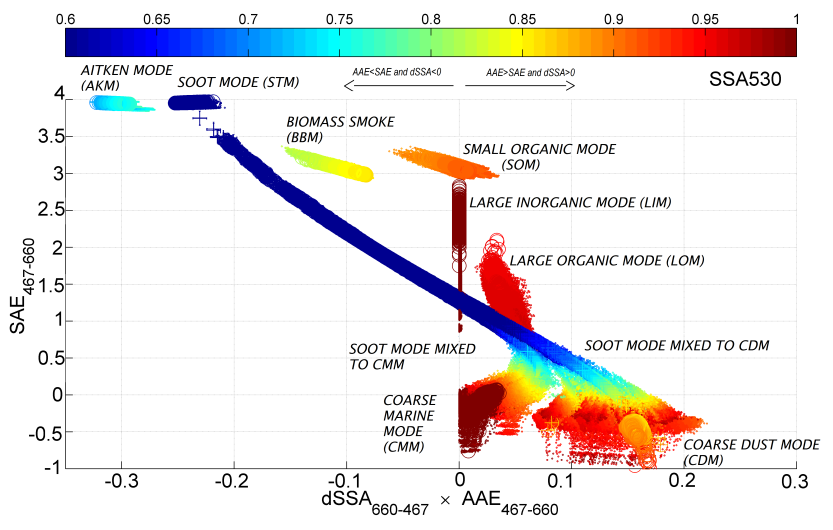

Fig. 4. Results of the numerical simulations illustrating the "paradigm" proposed to classify aerosol populations. All sets (indicated by the "o" markers) represent pure aerosol types but the mixed soot (STM+CCM or STM plus CDM indicated by "+" markers.) Note that large circle dots show calculations with refractive index $m=\bar{m}\left(\lambda, D_{\mathrm{p}}\right)$, and point dots with the $m=\bar{m}\left(\lambda, D_{\mathrm{p}}\right) \pm \delta m\left(\lambda, D_{\mathrm{p}}\right)$ used for the sensitivity analysis.

Our paradigm is based on the observation that (cf. Sect. 3) a combination of dSSA and AAE shall correlate to SAE. The correlation is based on the fact that (i) SAE is the scattering spectral variation (depending mainly on particle size); (ii) $\mathrm{AAE}$ is the absorption spectral variation (mainly depending on particle composition); and (iii) dSSA is the spectral variation of a combination of scattering and absorption (the SSA, depending on both particle size and composition). Therefore, the simpler SAE vs. dSSA relation (Fig. 1 and Fig. S1) is partly incomplete: it fails in separating aerosols with similar particle sizes and different composition. By way of evidence one might note that the SAE vs. dSSA plot is ineffective in separating aerosols with same particle diameters from 80 to $300 \mathrm{~nm}$ (typically classified as "urban pollution"), but different composition. They are here represented by SOM and BBM (and by some AKM, LIM and LOM). Both SOM and BBM have (Fig. 3) dSSA approaching zero and similar SAE (and similar SSA as well).

Contrarily, the paradigm built on dSSA.AAE as x-axis (instead of dSSA only) is more complete. The inverse relation between AAE and dSSA (simulated in Fig. 3) is based on the fact that both parameters vary with varying aerosol composition. This relation is effective in separating aerosols with similar SAE. This is the case of urban pollution aerosols, for which dSSA approaches zero. In this case, AAE is high enough, and largely varying with varying aerosol type, to show variations caused by particle composition, which are required to separate BBM from SOM.

"Regions" in which every single aerosol population - if alone - is expected to "move" the relation between SAE and dSSA.AAE come out as the following:

- coarse mode particles (CDM and CMM) lie in the region where $\mathrm{dSSA}_{660-467} \cdot \mathrm{AAE}_{467-660}>0$,
$\mathrm{SAE}_{467-660}<0.5$, and $\mathrm{SSA}_{530}>0.8, \mathrm{CDM}$ having lower $\mathrm{SSA}_{530}$ and larger $\mathrm{dSSA}_{660-467} \cdot \mathrm{AAE}_{467-660}$ (absolute values) than CMM has;

- large accumulation mode particles (LIM and LOM) are located in the area with $-0.01<\mathrm{dSSA}_{660-467}$. $\mathrm{AAE}_{467-660}<0.07, \quad 0.5<\mathrm{SAE}_{467-660}<3, \quad$ and $\mathrm{SSA}_{530}>0.9$, LOM having lower $\mathrm{SSA}_{530}$ and larger $\mathrm{dSSA}_{660-467} \cdot \mathrm{AAE}_{467-660}$ (absolute values) than LIM has;

- the small accumulation mode (BBM and SOM) drives data towards the area with $-0.15<\mathrm{dSSA}_{660-467}$. $\mathrm{AAE}_{467-660}<0.1, \mathrm{SAE}_{467-660}>1.5$, and $\mathrm{SSA}_{530}>$ 0.8 , BBM having lower $\mathrm{SSA}_{530}$ than SOM has;

- 60-120 nm particles (STM and AKM) fall in the upper left part of Fig. 4; when STM is combined to $\mathrm{CDM}$ or CMM, the resulting soot dominated mixed aerosol fall in the elongated blue and green area having $\mathrm{SSA}_{530}<0.8,0<\mathrm{SAE}_{467-660}<3$ and $-0.2<$ $\mathrm{dSSA}_{660-467} \cdot \mathrm{AAE}_{467-660}<0.2$.

Overall, further relevant "directions" appear:

- an increased absorption tends to decrease $\mathrm{SAE}_{467-660}$ and increase $\mathrm{dSSA}_{660-467} \cdot \mathrm{AAE}_{467-660}$ (absolute value);

- a change in $D_{\mathrm{p}}$ results in a decrease of $\mathrm{EAE}_{467-660}$ in the case of both large $D_{\mathrm{p}}$ (coarse mode) and small $D_{\mathrm{p}}$ (STM and AKM), the smaller particles (AKM and STM) mode being separated from the coarse mode by its lower $\mathrm{SSA}_{530}$ (note that the largest $\mathrm{EAE}_{467-660}$ occurs for fine (SOM and LIM) particles);

- dSSA $_{660-467}$ is determined by the comparison between $\mathrm{AAE}_{467-660}$ and $\mathrm{SAE}_{467-660}$, with $\mathrm{dSSA}_{660-467}<0$ for $\mathrm{AAE}_{467-660}<\mathrm{SAE}_{467-660}$, and dSSA $660-467>0$ for $\mathrm{AAE}_{467-660}>\mathrm{SAE}_{467-660 \text {. }}$

\subsection{Intensive optical properties observed for the key aerosol populations}

Results in Fig. 4 suggest the existence of a general paradigm to separate the observed aerosol populations. The combination of the paradigm with the measurements is useful to explain observations. Table 3 presents a reanalysis of the measurements (Fig. 2) in that context. It shows the relevant intensive optical properties resulting for the key urban aerosol populations.

Overall, the populations with a high $m_{\operatorname{Im}}\left(\lambda, D_{\mathrm{p}}\right)$ (see Table 2) are separated into two regions by the threshold of $\mathrm{AAE}_{467-660}=2$. In the region with $\mathrm{AAE}_{467-660}>2$ (Fig. 2a-c and $\mathrm{f}-\mathrm{h}$ ) the absorption is dominated by SOM, LOM and CDM. In this region, SOM, LOM, and CDM are clearly separated by their $\mathrm{SAE}_{467-660}$, SAE decreasing with 
Table 3. Intensive optical properties (SSA, SAE, AAE, and dSSA) of key aerosol populations (A.P.) resulting from the work, and related total particle number concentration $(N)$.

\begin{tabular}{llllll}
\hline A.P. & SSA $_{530}$ & SAE $_{467-660}$ & AAE $_{467-660}$ & dSSA $_{660-467}$ & $N_{7}\left(\#_{\left.\mathrm{cm}^{-3}\right)}\right.$ \\
\hline AKM & $<0.8$ & $\approx 4$ & $\approx 2$ & $<-0.1$ & $>5 \times 10^{4}$ \\
STM & $<0.8$ & $\approx 4$ & $<1.5$ & $<-0.1$ & $>5 \times 10^{4}$ \\
SOM & $>0.85$ & $1.5-3.5$ & $>2.5$ & $-0.1-0.1$ & $<2 \times 10^{4}$ \\
BBM & $<0.85$ & $1-3$ & $<2$ & $-0.15-0.05$ & $<2 \times 10^{4}$ \\
LIM & $>0.95$ & $0.5-3$ & $\approx 2.5$ & $0-0.01$ & $<10^{4}$ \\
LOM & $>0.9$ & $0.5-2$ & $>2.5$ & $0-0.1$ & $<10^{4}$ \\
CMM & $>0.95$ & $<0.5$ & $>2$ & $0-0.05$ & $<10^{4}$ \\
CDM & $>0.85$ & $<0.5$ & $\approx 2$ & $0.05-0.3$ & $<10^{4}$ \\
\hline
\end{tabular}

increasing $D_{\mathrm{p}}$ (cf. Fig. 3a). SOM, which is intended to represent organic compounds (may include nitrates) in the "condensation mode", is found in Fig. 2a, b (and Fig. 2f, g) for $\mathrm{SAE}_{467-660}>1.5$ and $\mathrm{AAE}_{467-660}>2.5$. In the region of $\mathrm{AAE}_{467-660}>2$, there are LOM (Fig. 2a, b, and equivalent Fig. 2f, g) for $0.5<\mathrm{SAE}_{467-660}<2$, and CDM (Fig. 2b, c and equivalent Fig. $2 \mathrm{~g}, \mathrm{~h}$ ) for $\mathrm{SAE}_{467-660}<0.5$. Both CMM and LIM lie in the same region of $\mathrm{AAE}_{467-660}>2$ (Fig. 2a, and equivalent Fig. 2f), the two aerosol populations having the lowest $m_{\operatorname{Im}}\left(\lambda, D_{\mathrm{p}}\right)$.

$\mathrm{AAE}_{467-660}<2$ highlights a region where STM and BBM are the dominant light absorbing components of the aerosol. Despite their similarities in composition, STM and BBM are clearly separated by the paradigm. STM is in the panels d, e (and equivalent i, l) of Fig. 2; when mixed to coarse particles, it can show $\mathrm{SAE}_{467-660}<1$ and $\mathrm{dSSA}_{660-467} \cdot \mathrm{AAE}_{467-660}>$ 0.5 . BBM is conversely in the panels $\mathrm{c}, \mathrm{d}$, e and equivalent h, i, 1 of Fig. 2 for larger SSA and lower N than STM. Indeed, they have different $\mathrm{SSA}_{530}$ (Fig. 3c), SSA being lower for STM than for BBM. They also show different dSSA $_{660-467}$ : STM has dSSA greater than BBM as absolute value. dSSA $660-467$. AAE $_{467-660}$ is, finally, larger (absolute value) for STM (Fig. 3d). In fact, they represent aerosol populations with different chemical and physical properties, as well as light absorbing properties (e.g., Han et al., 2010). STM is intended to represent fresh combustion generated particles (soot mode). Soot mode particles consist of both BC and OC, the particle size ranging from 30-200 nm mainly in the Aitken mode, with complex mixing state in the atmosphere (e.g., Seinfeld and Pandis, 2006). BBM is intended to represent a BC-rich aerosol aged in the atmosphere. BBM aerosol is typically associated with the smoke of burning vegetation, with BBM particles generally in the $150-400 \mathrm{~nm}$ size range (e.g., Clarke et al., 2007). BBM and STM represent here only special cases of the "real" soot mode and biomass burning smoke aerosols. In real cases the $D_{\mathrm{p}}$ and the OM content can vary more than that simulated here. Also, real aerosols are rarely "pure" types, but more often mixed as in the case of STM plus CMM in Fig. 4. In fact, the fresher the emissions, the smaller the $D_{\mathrm{p}}$ of both STM and BBM
- this should translate into lower $\mathrm{EAE}_{467-660}, \mathrm{AAE}_{467-660}$, and $\mathrm{SSA}_{530}$ (see Fig. 3a-c). Conversely, the more aged the aerosol is, the larger the $D_{\mathrm{p}}$ - this should move, e.g., the BBM towards the LOM in Fig. 4 and should translate into lower $\mathrm{SAE}_{467-660}$. Furthermore, the larger the OM content of the combustion emissions (the $D_{\mathrm{p}}$ size range being the same), the larger the $\mathrm{AAE}_{467-660}$ and $\mathrm{SAE}_{467-660}$ - this should result in BBM "moving" towards SOM, and STM towards AKM in Fig. 4.

$\mathrm{EAE}_{467-660}$ of STM can be as low $(<1.5)$ as EAE $467-660$ of CDM. Moreover, $\mathrm{SAE}_{467-660}<1$, generally attributed to coarse particles, can also represent mixed aerosols strongly dominated by soot mode particles. Despite the similar $\mathrm{SAE}_{467-660}$ and the similar $\mathrm{dSSA}_{660-467} \cdot \mathrm{AAE}_{467-660}$ (Fig. 3a, d), soot particles (STM) added to coarse dust $(\mathrm{CDM})$ are however separated from the pure coarse dust by a different $\mathrm{SSA}_{530}$, CDM having $\mathrm{SSA}_{530}>0.85$ and STM+CDM having $\mathrm{SSA}_{530}<0.85$. Note that (Fig. 3) CDM shows $\mathrm{SSA}_{530}$ decreasing with increasing $D_{\mathrm{p}}$, and $\mathrm{dSSA}_{660-467} \cdot \mathrm{AAE}_{467-660}$ increasing with increasing $D_{\mathrm{p}}$. Conversely, STM shows SSA $_{530}$ decreasing with decreasing $D_{\mathrm{p}}$, and $\mathrm{dSSA}_{660-467} \cdot \mathrm{AAE}_{467-660}$ decreasing with decreasing $D_{\mathrm{p}}$. These tendencies are on the basis of the inverse relationship found between $\mathrm{SAE}_{467-660}$ and $\mathrm{dSSA}_{660-467}$. AAE $467-660$ in Fig. 1.

The simulated ultrafine particles (both STM and AKM) show rather low EAE $467-660 \quad(<2$ for STM, and $<3$ for AKM). This probably results from combining their absorption properties $\left(m_{\operatorname{Im}}\left(\lambda, D_{\mathrm{p}}\right)>0\right)$ with their small $D_{\mathrm{p}}$. Assuming no absorbtion for AKM $\left(m_{\operatorname{Im}}\left(\lambda, D_{\mathrm{p}}\right)=0\right)$, Mie calculations translates to $\mathrm{EAE}_{467-660}=4$ (Rayleigh scattering regime). We conversely simulated AKM to have $m_{\operatorname{Im}}\left(\lambda, D_{\mathrm{p}}\right)>0$, slightly varying with varying $\lambda$. The $m_{\text {Im }}\left(\lambda, D_{\mathrm{p}}\right)>0$ is actually intended to represent their likely content of OM, which has been argued to be more than $20 \%$ in the urban background (Pohjola et al., 2007). The light variability of $m_{\operatorname{Im}}\left(\lambda, D_{\mathrm{p}}\right)$ with $\lambda$ is intended to represent that this OM is not the refractory organic carbon typical of some biomass burning aerosols (Clarke et al., 2007). This assumption was corroborated by our experimental observations: 
AKM shows up in Fig. 2c, d, e (and equivalent Fig. 2h, i, 1), the $\mathrm{AAE}_{467-660}$ of AKM dominated aerosols being $\leqq 2$.

Ultrafine particles considered here (both STM and AKM) have rather low $\mathrm{SSA}_{530}$. Although expected for the soot (STM) (e.g., Moffet and Prather, 2009), this result might be atypical for AKM. In fact, the numerical simulation (Fig. 3c) shows that $\mathrm{SSA}_{530}$ (and $\mathrm{SSA}_{467}$ ) sharply decreases in the Aitken mode size range as a function of particle size, affecting both the STM and the AKM results. The change may be even stronger in the "real" atmosphere, where changes in particle size are associated with changes in chemical composition and mixing state. Conversely, the numerical simulation hypothesizes a fixed chemical composition (that is a fixed $\left.m\left(\lambda, D_{\mathrm{p}}\right)\right)$ for a given aerosol population size range.

The AAE $467-660$ of STM dominated aerosols (Fig. 2d, e) is $>1$ (it varies from 1 to 1.5 ). This is likely because our site is reached by soot shortly aged in the atmosphere (less than $1 \mathrm{~h}$ ) rather than very fresh soot. The OM content can increase with increasing the degree of aging of soot in the atmosphere (e.g., Moffet and Prather, 2009). We therefore simulated STM (Table 2) by a $m_{\operatorname{Im}}\left(\lambda, D_{\mathrm{p}}\right)$ smaller than values usually found in the literature (e.g., Alexander et al., 2008). Several of those works furthermore refer to individual soot carbon particles rather than to bulk atmospheric aerosols like in our case. Finally, very fresh individual soot mode particles do not have the spherical shape requested for a correct simulation by the Mie theory used here.

\subsection{Comparison to previous works}

In this section we compare our findings to previous works. The aim is to demonstrate the general validity of the relations observed (the paradigm in Fig. 4). The comparison with previous measurements is possible as the intensive aerosol parameters addressed do not strictly depend on local conditions (e.g., number concentrations, scattering and absorption coefficients).

A comparison between the paradigm (Fig. 4) and observations taken during major field campaigns (Table 4) is proposed in Fig. 5, which shows nice agreement. (Note that shaded areas in Fig. 5 sketch the simulation results of Fig. 4, and that the color of the points in Fig. 5 is coded according to $\mathrm{SSA}_{530}$ as in Fig. 4.) Among others, biomass burning observed in African savannah and Zambia (case 1 in Fig. 5 and Table 4), in southern Africa during SAFARI (case 2), and in Asia during the EAST-AIRE (case 4) are shown to match quite well the direction of the BBM simulations. Urban/industrial and mixed aerosol in Greenbelt, USA (case 3 ), aerosol mixed downwind of the US Atlantic coast during ICARTT (case 5), urban/industrial mixed aerosols in Mexico City measured by remote sensing (case 6) and in situ (case 7 ), and pollution aerosols with high sulfate content (case 13) are shown to fall between the regions of LIM, LOM and the mixed Aitken mode, which are typical of urban areas. In the coarse mode, the desert dust and oceanic aerosol in Cape

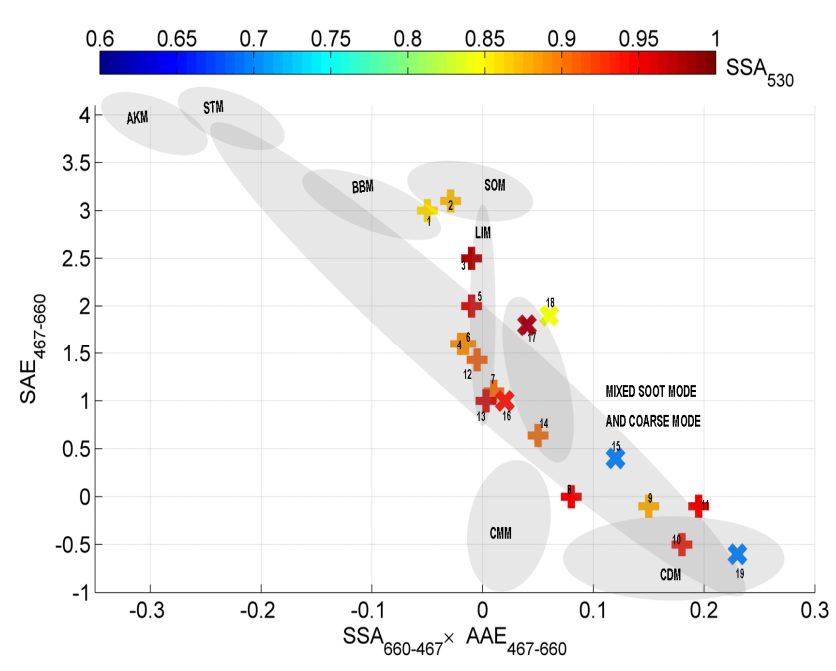

Fig. 5. Comparison between the aerosol classification paradigm proposed and observations taken during previous field campaigns (Table 4). The symbol "+" indicates previous observations, and " $\times$ " indicates observations from this work, both of them being color coded by SSA. Note that shaded areas are intended to reproduce the numerical results showed in Fig. 4.

Verde (case 8), and the Saharan dust during PRIDE (case 10) are shown to fit the region between CDM and CMM. The cases of dust + urban + industrial during ACE-Asia (case 9) and $\mathrm{BC}+$ dust sampled in Mexico City during MILAGRO (case 11) match quite well the STM plus CDM approximations.

The cases from 15 to 19 were measured during this study (Sect. 4.2) and are included for comparison. They address aerosol populations not shown in the previous cases 1-14. Cases 15 and 19 show mixed aerosols dominated by STM particles as observed in Fig. 21 (and equivalent Fig. 2d) for $\mathrm{SSA}_{530}<0.8, N_{7}>5 \times 10^{4} \mathrm{\# cm}^{-3}$, and $\mathrm{SAE}_{467-660}<1$. Case 16 shows an urban aerosol with a dominant AKM (large $N_{7}$, but low absorption coefficients $\sigma_{\mathrm{p}}$, not shown here) as observed in Fig. 2h (and equivalent Fig. 2c) for $N_{7}>7 \times 10^{4} \mathrm{\# cm}^{-3}$, and $\mathrm{SAE}_{467-660} \approx 1.5$. Cases 17 and 18 show aerosols dominated by SOM and LOM, as observed in Fig. 2a, b (and Fig. 2f,g) for $\mathrm{AAE}_{467-660}>2.5$, $\mathrm{SAE}_{467-660}>1.5$, and $N_{7}<10^{4} \# \mathrm{~cm}^{-3}$.

The paradigm therefore fits in previous works. By way of illustration, it might be interesting to compare it (cf. Fig. 4, and Fig. 1 and Fig. S1) also to Fig. 5 from Russell et al. (2010). The comparison reveals that both ways of analyzing data reach very similar conclusions and allow optical classification:

- the "urban/industrial" aerosol type cluster $(\mathrm{AAE}=0.8$ $1.5, \mathrm{EAE}=1.5-1.8)$ of Russell et al. (2010), here represented by the mixed Aitken mode (e.g., STM+CMM) aerosol population $(\mathrm{AAE} \sim 2, \mathrm{SAE}=1-2.5)$; 
Table 4. Observations of aerosol populations (A.P.) considered for the comparison to the aerosol classification paradigm drawn in Fig. 5. (Numbers in Fig. 5 represent the ID showed here.)

\begin{tabular}{cllll}
\hline ID & A.P. & Description & Observations & Reference \\
\hline 1 & BBM & African savannah & Remote sensing & Dubovik et al. (2002) \\
2 & BBM & SAFARI, southern Africa, biomass smoke & Remote sensing & Russell et al. (2010) \\
3 & Mixed & Urban/industrial mixed, Greenbelt93-00 & Remote sensing & Dubovik et al. (2002) \\
4 & BBM & EAST-AIRE, biomass burning & In situ & Yang et al. (2009) \\
5 & Mixed & ICARTT, downwind of US coast urban aerosols & Remote sensing & Russell et al. (2010) \\
6 & Mixed & Urban/industrial mixed, Mexico City & Remote sensing & Dubovik et al. (2002) \\
7 & Mixed & MILAGRO, flights over Mexico City, BC+OM & In situ & Bergstrom et al. (2010) \\
8 & CMM+CDM & Desert dust, oceanic, Cape verde & Remote sensing & Dubovik et al. (2002) \\
9 & Mixed & ACE Asia, dust urban/industrial & Remote sensing & Russell et al. (2010) \\
10 & CDM & PRIDE, saharan dust & Remote sensing & Russell et al. (2010) \\
11 & Mixed & MILAGRO, flights over Mexico City, BC+Dust & In situ & Bergstrom et al. (2010) \\
12 & LOM+LIM & Pollution 1 (higher OC/EC ratio) & In situ & Lee et al. (2012) \\
13 & LIM+mixed & Pollution 2 (higher nss-sulfate/EC ratio) & In situ & Lee et al. (2012) \\
14 & CDM+LOM & Pollution + Dust & In situ & Lee et al. (2012) \\
15 & StM+mixed & Urban+ downwind of soot emissions from aircraft & In situ & This work \\
16 & AKM+mixed & Urban pollution + Aitken mode & In situ & This work \\
17 & LOM & Scattering accumulation mode particles & In situ & This work \\
18 & SOM+LOM & Organic accumulation mode particles & In situ & This work \\
19 & mixed STM & Urban mixed soot mode & In situ & This work \\
\hline
\end{tabular}

- the "biomass burning" aerosol type cluster (AAE $=1-$ 1.7, $\mathrm{EAE}=1.8-2$ ) of Russell et al. (2010), here represented by the BBM aerosol population $(\mathrm{AAE}<2, \mathrm{SAE}=1-3)$;

- the "desert dust" aerosol type cluster (AAE $=1.5-2.5$, $\mathrm{EAE}=0.2-1)$ of Russell et al. (2010), here represented by the $\mathrm{CDM}$ aerosol population (AAE $\sim 2, \mathrm{SAE}<0.5$ ).

Also, the comparison shows that the paradigm in Fig. 4 has the effect of putting the aerosol observations into a more general framework. It is the $\mathrm{SAE}_{467-660} / \mathrm{AAE}_{467-660}$ ratio determining $\mathrm{dSSA}_{660-467}$, the relation being inversely linear (dSSA $660-467$ increases with decreasing $\left.\mathrm{SAE}_{467-660} / \mathrm{AAE}_{467-660}\right)$. Aerosols show therefore $\mathrm{dSSA}_{660-467}<0$ if $\mathrm{SAE}_{467-660} / \mathrm{AAE}_{467-660}>1$, and vice versa $\mathrm{dSSA}_{660-467}>0$ if $\mathrm{SAE}_{467-660} / \mathrm{AAE}_{467-660}<1$ (cf. Table 4).

Coarse particles plus soot mode particles (STM) show invariably dSSA $660-467>0$ for $\mathrm{SAE}_{467-660} / \mathrm{AAE}_{467-660}<1$. Conversely, accumulation mode particles show two different conditions: (i) for large $\mathrm{BC}$ content $\left(\mathrm{AAE}_{467-660}<2\right.$, e.g., BBM) they show $\mathrm{dSSA}_{660-467<0}$ $\left(\mathrm{SAE}_{467-660} / \mathrm{AAE}_{467-660}>1\right)$; (ii) for large $\mathrm{OM}$ contents $\left(\mathrm{AAE}_{467-660}>2\right.$, e.g., SOM and LOM) they show $\mathrm{dSSA}_{660-467}>0\left(\mathrm{SAE}_{467-660} / \mathrm{AAE}_{467-660}<1\right)$. The latter case goes along with the conclusion by Russell et al. (2010) that for biomass burning the $\mathrm{BC}$ should cause a dSSA $<0$ (biomass burning in BBM), whereas the OM should be characterized by a dSSA $>0$ (biomass burning in SOM). The authors analyzed the case of Mexican aerosol sampled by a C-130 during the MILAGRO campaign, in which an in- creased organic mass fraction caused the slope of SSA with $\lambda$ to change from negative to positive. They speculated that for biomass burning smoke, the $\mathrm{BC}$ can outweigh the $\mathrm{OM}$ and produce dSSA $<0$. Similarly, the aging degree of the aerosol in the atmosphere can change its $\mathrm{SAE}_{467-660} / \mathrm{AAE}_{467-660}$ ratio. Albeit with obvious limitations, the paradigm shows similar changes. This is the case mentioned in the Sect. 4.2, in which the aging in the atmosphere of BBM particles translates into lower $\mathrm{SAE}_{467-660}$ and higher $\mathrm{AAE}_{467-660}$ (and $\mathrm{dSSA}_{660-467}>0$ ), which is a shift towards LOM. A similar result was also obtained by Müller et al. (2007), who found the EAE of forest fire smoke decreasing for increasing transport time (and increasing effective radius) in the atmosphere.

The paradigm shows that dSSA $660-467<0$ (Fig. 4) can be attributed to BBM (e.g., biomass smoke) and AKM (fresh urban aerosols). Both cases have $\mathrm{SSA}_{530}<0.9$. This result is supported by the observations (Fig. 2) showing no case of dSSA $<0$ for $\mathrm{SSA}_{530}>0.95$ (Fig. 2a) and few cases of dSSA $<0$ for $0.9<$ SSA $_{530}<0.95$ (Fig. 2b). Observations highlight that most of the dSSA $<0$ cases show AAE $_{467-660}<2$. Similar results were also observed by Russell et al. (2010): they showed (Fig. 3 of their paper) that, for SSA $>0.9$, SSA increases with wavelength $(\mathrm{dSSA}>0)$ and with increasing AAE, with dSSA being always positive but for $\mathrm{AAE}=1.4$ (the only case representing low AAEs).

Clearly, there is difficulty in rigorously evaluating the optical properties of the Aitken mode without accurate measurements of their size, refractive index and mixing state. Albeit with caution, our findings (Fig. 4) are open to new 
explanations. They can explain situations in which the contemporary observation of low EAEs and low SSAs was (probably erroneously) attributed only to coarse mode particles, with limited consideration for the Aitken mode. The case 19 in Fig. 5 and Table 4 shows a similar situation with mixed aerosol dominated by $\mathrm{BC}$ in the soot mode. The paradigm can explain this case with $\mathrm{SAE}_{467-660}$ down to -0.5 and no dust - only urban coarse particles. Similar observations of BC pollution plumes with SAE below 1 are not new (Clarke et al., 2007; Raut et al., 2009; Doherty et al., 2005). Raut et al. (2009) observed unclear and contrasting results in a subway environment in a Paris railway station, with low SAE and small SSA during the train passage. The observations were attributed to both the presence of absorbing iron oxides and the internally generated $\mathrm{BC}$ from the degradation of carbonaceous brake components. Clarke et al. (2007) observed SAE of approximately 1 for some apparent pollution data (in the related Fig. 8) and concluded those pollution data to be exceptions, successively explained to be dust. Doherty et al. (2005) observed a composite relation from three in situ research platforms during the ACE-Asia campaign: aerosol dominated by pollution, sea salt and dust showed SSA as low as 0.75 , and SAE being approximately 1 . Unfortunately, we could not include those works in Fig. 5 because the relevant data did not contain all the necessary information to fill the paradigm. However, our work indicates that the reanalysis of similar situations in the proposed framework of Fig. 4 can provide quite robust explanations.

Through the combined analysis of spectral optical properties, the paradigm furthermore provides insights into aerosol particle size and chemical composition. The proposed paradigm may complete previous aerosol classifications based on SAE, AAE, and SSA in which unclear situations were found. It might help in separating polluted and clean days (e.g., Gyawali et al., 2012) and dust and polluted dust (e.g., Lee et al., 2012), unraveling aerosol mixtures (e.g., Yang et al., 2009), understanding strange cases (e.g., Clarke et al., 2007), or revealing the contribution of absorption in classifying aerosol properties (e.g., Gobbi et al., 2007). It is worth mentioning that our paradigm still works with the often-used extinction Angstrom exponent (EAE) rather than SAE. Nevertheless, in that case the inverse relationship in Fig. 1 is less clear (and the correlation $R^{2}$ lower) because unlike the SAE, the $\mathrm{EAE}_{467-660}$ still combines both scattering and absorption information, thus not exploiting the specific role of absorption and its full potential.

Lastly, it should be noted that the paradigm (Fig. 1) has been filled in by surface in situ aerosol data. When attempting a comparison between the paradigm filled in by similar surface measurements data and data measured by remote sensing techniques (e.g., columnar aerosol data from AERONET), some differences can occur. Differences can be due to several factors: (1) Contrary to remote sensing data, surface in situ datasets generally include 24-h (day and night, all sky conditions) measurements with 1- to 5-min resolution. (2) The contribution of local emissions, particularly soot particles (here referred to as STM) to the bulk aerosol is expected to be large in in situ data: STM can be very abundant at the surface and can often dominate surface in situ aerosol data, contrary to columnar observations. Being extremely diluted over columnar aerosols observations, STM can be less evident in the case of AERONET data, soot particles rarely dominating columnar aerosol observations. (3) Differences can be due to the way in situ measurements "observe" aerosols: in situ instruments measure dry aerosols while AERONET observes, on the contrary, aerosols as they are in the atmosphere (i.e., hydrated aerosols). Aerosol hydration is really effective in changing both particle refractive index and size distribution.

\section{Conclusions}

Spectral optical properties of aerosol particles contain an outstanding set of information on their size and composition. Extracting this piece of information is crucial in order to obtain an optical classification scheme of aerosol. This is the backdrop of this work, in which two years' measurements of aerosol optical properties (scattering and absorption coefficients at blue, green and red wavelengths $(\lambda)$ ) were collected at a suburban background site (Rome, Italy) together with measurements of particle number size distributions. Size distribution measurements were coupled to relevant optical simulations (Mie theory) to highlight the relative contribution of particle size $\left(D_{\mathrm{p}}\right)$ and refractive index $\left(m\left(\lambda, D_{\mathrm{p}}\right)\right)$ on the bulk aerosol properties.

The results of the work proved useful in drawing a general "paradigm" to classify aerosol types. The paradigm was based on aerosol spectral scattering and absorption, namely scattering and absorption Angstrom exponents, SAE and AAE, and the spectral single scattering albedo, dSSA. In the framework of this classification scheme, key atmospheric aerosol populations were optically identified including soot, urban Aitken mode particles, biomass burning, organic and inorganic particles, dust and marine aerosols. Conclusions drawn from these results highlight the following:

- aerosol populations show distinctive combinations of SAE and dSSA - AAE, those variables being linked by an inverse linear relationship varying with varying SSA;

- aerosol populations exhibit a dSSA depending on the $\mathrm{SAE} / \mathrm{AAE}$ ratio, with $\mathrm{dSSA}<0$ for $\mathrm{SAE} / \mathrm{AAE}>1$ (e.g., biomass smoke rich in black carbon), and dSSA $>0$ for SAE/AAE $<1$ (e.g., dust plus soot);

- increasing particle absorption decreases EAE and SAE; coarse (e.g., dust) and soot mode aerosols can show $\mathrm{EAE}<1.5$ whilst accumulation mode aerosols show $\mathrm{EAE}>1.5$; 
- similar to soot, urban Aitken mode particles show an imaginary part of $m\left(\lambda, D_{\mathrm{p}}\right)$ greater than 0 resulting in SSA $<0.8$, whilst fine and coarse aerosols (including dust) show $\mathrm{SSA}>0.8$;

- atmospheric urban aerosols exhibit the largest EAEs in the accumulation mode size range of $100-300 \mathrm{~nm}$; in the ultrafine size range EAE is lower $(<2)$, with the lowest values (down to 1.5 ) being reached in the soot mode (STM).

The work finally presented a comparison between the proposed aerosol classification scheme and observations taken during previous field campaigns. The comparison shows good agreement. This result indicates both the general validity of the proposed relationships, and the possibility of providing additional interpretations to previous and future works. Nevertheless, besides adding new relevant data, outcomes of this work may be important to improve current parameterizations of climate models and to provide a more accurate characterization of the atmospheric load of carbonaceous aerosols from satellite measurements.

\section{Supplementary material related to this article is available online at: http://www.atmos-chem-phys.net/13/ 2455/2013/acp-13-2455-2013-supplement.pdf.}

Acknowledgements. The work was partly accomplished in the framework of the DIAPASON ("Desert-dust Impact on Air quality through model-Predictions and Advanced Sensors ObservatioNs") project, funded by the European Commission (LIFE+ 2010 ENV/IT/391). Measurements of particle numbers were supported by the Italian Ministry of Health, and the Department of Epidemiology of the ASL RM/E in the framework of the project "Impact of atmospheric pollution by airports on citizens health". We also thank G. Cattani for his support.

Edited by: E. Gerasopoulos

\section{References}

Ackerman, P. and Toon, O. B.: Absorption of visible radiation in atmosphere containing mixtures of absorbing and nonabsorbing particles, Appl. Opt., 20, 3661-3668, 1981.

Alexander, D. T. L., Crozier, P. A., and Anderson, J. R.: Brown carbon spheres in East Asian outflow and their optical properties, Science, 321, 833-835, 2008.

Anderson, T. L. and Ogren, J. A.: Determining aerosol radiative properties using the TSI 3563 integrating nephelometer, Aerosol Sci. Tech., 29, 57-69, 1998.

Andreae, M. O. and Gelencsér, A.: Black carbon or brown carbon? The nature of light-absorbing carbonaceous aerosols, Atmos. Chem. Phys., 6, 3131-3148, doi:10.5194/acp-6-3131-2006, 2006.
Barnaba, F. and Gobbi, G. P.: Aerosol seasonal variability over the Mediterranean region and relative impact of maritime, continental and Saharan dust particles over the basin from MODIS data in the year 2001, Atmos. Chem. Phys., 4, 2367-2391, doi:10.5194/acp-4-2367-2004, 2004.

Basart, S., Pérez, C., Cuevas, E., Baldasano, J. M., and Gobbi, G. P.: Aerosol characterization in Northern Africa, Northeastern Atlantic, Mediterranean Basin and Middle East from direct-sun AERONET observations, Atmos. Chem. Phys., 9, 8265-8282, doi:10.5194/acp-9-8265-2009, 2009.

Bergstrom, R. W.: Extinction and absorption coefficients of the atmospheric aerosol as a function of particle size, Beitr. Phys. Atmos., 46, 223-234, 1973.

Bergstrom, R. W., Russell, P. B., and Hignett, P.: Wavelength dependence of the absorption of black carbon particles: predictions and results from the TARFOX experiment and implications for the aerosol single scattering albedo, J. Atmos. Sci., 59, 567-577, 2002.

Bergstrom, R. W., Pilewskie, P., Russell, P. B., Redemann, J., Bond, T. C., Quinn, P. K., and Sierau, B.: Spectral absorption properties of atmospheric aerosols, Atmos. Chem. Phys., 7, 5937-5943, doi:10.5194/acp-7-5937-2007, 2007.

Bergstrom, R. W., Schmidt, K. S., Coddington, O., Pilewskie, P., Guan, H., Livingston, J. M., Redemann, J., and Russell, P. B.: Aerosol spectral absorption in the Mexico City area: results from airborne measurements during MILAGRO/INTEX B, Atmos. Chem. Phys., 10, 6333-6343, doi:10.5194/acp-10-63332010, 2010.

Bond, T. C.: Spectral dependence of visible light absorption by carbonaceous particles emitted from coal combustion, Geophys. Res. Lett., 28, 4075-4078, 2001.

Bond, T. C. and Bergstrom, R. W.: Light absorption by carbonaceous particles: an investigative review, Aerosol Sci. Tech., 40, 27-67, 2006.

Bond, T. C., Anderson, T. L., and Campbell, D.: Calibration and intercomparison of filter-based measurements of visible light absorption by aerosols, Aerosol Sci. Tech., 30, 582-600, 1999.

Bond, T. C., Covert, D. S., and Müller, T., Truncation and angularscattering corrections for absorbing aerosol in the TSI 3563 nephelometer, Aerosol Sci. Tech., 43, 866-871, 2009.

Cai, Y., Montague, D. C., and Deshler, T.: Comparison of measured and calculated scattering from surface aerosols with an average, a size-dependent, and a time-dependent refractive index, J. Geophys. Res., 116, D02202, doi:10.1029/2010JD014607, 2011.

Cappa, C. D., Lack, D. A., Burkholder, J. B., and Ravishankara, A. R.: Bias in filter-based aerosol light absorption measurements due to organic aerosol loading: evidence from laboratory measurements, Aerosol Sci. Tech., 42, 1022-1032, 2008.

Clarke, A., McNaughton, C., Kapustin, V., Shinozuka, Y., Howell, S., Dibb, J., Zhou, J., Anderson, B., Brekhovskikh, V., Turner, H., and Pinkerton, M.: Biomass burning and pollution aerosol over North America: organic components and their influence on spectral optical properties and humidification response, J. Geophys. Res., 112, D12S18, doi:10.1029/2006JD007777, 2007.

Costabile, F., Birmili, W., Klose, S., Tuch, T., Wehner, B., Wiedensohler, A., Franck, U., König, K., and Sonntag, A.: Spatiotemporal variability and principal components of the particle number size distribution in an urban atmosphere, Atmos. Chem. Phys., 9, 3163-3195, doi:10.5194/acp-9-3163-2009, 2009. 
Costabile, F., Amoroso, A., and Wang, F.: Sub- m particle size distributions in a suburban Mediterranean area. Aerosol populations and their possible relationship with HONO mixing ratios, Atmos. Environ., 44, 5258-5268, 2010.

Doherty, S. J., Quinn, P. K., Jefferson, A., Carrico, C. M., Anderson, T. L., and Hegg, D.: A comparison and summary of aerosol optical properties as observed in situ from aircraft, ship, and land during ACE-Asia, J. Geophys. Res., 110, D04201, doi:10.1029/2004jd004964, 2005.

Dubovik, O., Holben, B., Eck, T. F., Smirnov, A., Kaufman, Y. J., King, M. D., Tanré, D., and Slutsker, I.: Variability of absorption and optical properties of key aerosol types observed in worldwide locations, J. Atmos. Sci., 59, 590-608, 2002.

Flowers, B. A., Dubey, M. K., Mazzoleni, C., Stone, E. A., Schauer, J. J., Kim, S.-W., and Yoon, S. C.: Optical-chemicalmicrophysical relationships and closure studies for mixed carbonaceous aerosols observed at Jeju Island; 3-laser photoacoustic spectrometer, particle sizing, and filter analysis, Atmos. Chem. Phys., 10, 10387-10398, doi:10.5194/acp-10-10387-2010, 2010.

Gobbi, G. P., Barnaba, F., and Ammannato, L.: The vertical distribution of aerosols, Saharan dust and cirrus clouds in Rome (Italy) in the year 2001, Atmos. Chem. Phys., 4, 351-359, doi:10.5194/acp-4-351-2004, 2004.

Gobbi, G. P., Kaufman, Y. J., Koren, I., and Eck, T. F.: Classification of aerosol properties derived from AERONET direct sun data, Atmos. Chem. Phys., 7, 453-458, doi:10.5194/acp-7-453-2007, 2007

Gyawali, M., Arnott, W. P., Zaveri, R. A., Song, C., Moosmüller, H., Liu, L., Mishchenko, M. I., Chen, L.-W. A., Green, M. C., Watson, J. G., and Chow, J. C.: Photoacoustic optical properties at UV, VIS, and near IR wavelengths for laboratory generated and winter time ambient urban aerosols, Atmos. Chem. Phys., 12, 2587-2601, doi:10.5194/acp-12-2587-2012, 2012.

Han, Y. M., Cao, J. J., Lee, S. C., Ho, K. F., and An, Z. S.: Different characteristics of char and soot in the atmosphere and their ratio as an indicator for source identification in Xi' an, China, Atmos. Chem. Phys., 10, 595-607, doi:10.5194/acp-10-595-2010, 2010.

Holben, B. N., Eck, T. F., Slutsker, I., Tanre, D., Buis, J. P., Setzer, A., Vermote, E., Reagan, J. A., Kaufman, Y. J., Nakajima, T., Lavenu, F., Jankowiak, I., and Smirnov, A.: AERONET - a federated instrument network and data archive for aerosol characterization, Remote Sens. Environ., 66, 1-16, 1998.

Hinds, W. C.: Aerosol Technology, 2nd edn., John Wiley and Sons, New York, 1999.

Intergovernmental Panel on Climate Change: Fourth Assessment Report: Climate Change 2007: The AR4 Synthesis Report, Geneva: IPCC, available at: http://www.ipcc.ch/ipccreports/ ar4-wg1.htm, last access: 3 August 2010, 2007.

Kaufman, Y. J., Tanre, D., Dubovik, O., Karnieli, A., and Remer, L. A.: Absorption of sunlight by dust as inferred from satellite and ground-based remote sensing, Geophys. Res. Lett., 28, 1479-1482, 2001.

Kirchstetter, T. W., Novakov, T., and Hobbs, P.: Evidence that the spectral dependence of light absorption by aerosols is affected by organic carbon, J. Geophys. Res., 109, D21208, doi:10.1029/2004JD004999, 2004.

Kulmala, M., Asmi, A., Lappalainen, H. K., Baltensperger, U., Brenguier, J.-L., Facchini, M. C., Hansson, H.-C., Hov, Ø., O’Dowd, C. D., Pöschl, U., Wiedensohler, A., Boers, R.,
Boucher, O., de Leeuw, G., Denier van der Gon, H. A. C., Feichter, J., Krejci, R., Laj, P., Lihavainen, H., Lohmann, U., McFiggans, G., Mentel, T., Pilinis, C., Riipinen, I., Schulz, M., Stohl, A., Swietlicki, E., Vignati, E., Alves, C., Amann, M., Ammann, M., Arabas, S., Artaxo, P., Baars, H., Beddows, D. C. S., Bergström, R., Beukes, J. P., Bilde, M., Burkhart, J. F., Canonaco, F., Clegg, S. L., Coe, H., Crumeyrolle, S., D’Anna, B., Decesari, S., Gilardoni, S., Fischer, M., Fjaeraa, A. M., Fountoukis, C., George, C., Gomes, L., Halloran, P., Hamburger, T., Harrison, R. M., Herrmann, H., Hoffmann, T., Hoose, C., Hu, M., Hyvärinen, A., Hõrrak, U., Iinuma, Y., Iversen, T., Josipovic, M., Kanakidou, M., Kiendler-Scharr, A., Kirkevåg, A., Kiss, G., Klimont, Z., Kolmonen, P., Komppula, M., Kristjánsson, J.E., Laakso, L., Laaksonen, A., Labonnote, L., Lanz, V. A., Lehtinen, K. E. J., Rizzo, L. V., Makkonen, R., Manninen, H. E., McMeeking, G., Merikanto, J., Minikin, A., Mirme, S., Morgan, W. T., Nemitz, E., O’Donnell, D., Panwar, T. S., Pawlowska, H., Petzold, A., Pienaar, J. J., Pio, C., Plass-Duelmer, C., Prévôt, A. S. H., Pryor, S., Reddington, C. L., Roberts, G., Rosenfeld, D., Schwarz, J., Seland, Ø., Sellegri, K., Shen, X. J., Shiraiwa, M., Siebert, H., Sierau, B., Simpson, D., Sun, J. Y., Topping, D., Tunved, P., Vaattovaara, P., Vakkari, V., Veefkind, J. P., Visschedijk, A., Vuollekoski, H., Vuolo, R., Wehner, B., Wildt, J., Woodward, S., Worsnop, D. R., van Zadelhoff, G.-J., Zardini, A. A., Zhang, K., van Zyl, P. G., Kerminen, V.-M., S Carslaw, K., and Pandis, S. N.: General overview: European Integrated project on Aerosol Cloud Climate and Air Quality interactions (EUCAARI) - integrating aerosol research from nano to global scales, Atmos. Chem. Phys., 11, 1306113143, doi:10.5194/acp-11-13061-2011, 2011.

Jacobson, M. Z.: Strong radiative heating due to the mixing state of black carbon in atmospheric aerosols, Nature, 409, 695-697, 2001.

Lack, D. A., Cappa, C. D., Covert, D. S., Baynard, T., Massoli, P., Sierau, B., Bates, T. S., Quinn, P. K., Lovejoy, E. R., and Ravishankara, A. R.: Bias in filter-based aerosol light absorption measurements due to organic aerosol loading: evidence from ambient measurements, Aerosol Sci. Tech., 42, 1033-1041, 2008.

Lee, S., Yoon, S. C., Kim, S. W., Kim, Y. P., Ghim, Y. S., Kim, J. H., Kang, C. H., Kim, Y. J., Chang, L. S., and Lee, S. J.: Spectral dependency of light scattering/absorption and hygroscopicity of pollution and dust aerosols in Northeast Asia, Atmos. Environ., 50, 246-254, 2012.

Moffet R. C. and Prather, K. A.: In-situ measurements of the mixing state and optical properties of soot with implications for radiative forcing estimates, P. Natl. Acad. Sci., 106, 11872-11877, 2009.

Moosmüller, H., Chakrabarty, R. K., and Arnott, W. P.: Aerosol light absorption and its measurement: a review, J. Quant. Spectrosc. Ra., 110, 844-878, doi:10.1016/j.jqsrt.2009.02.035, 2009.

Moosmüller, H., Chakrabarty, R. K., Ehlers, K. M., and Arnott, W. P.: Absorption Ångström coefficient, brown carbon, and aerosols: basic concepts, bulk matter, and spherical particles, Atmos. Chem. Phys., 11, 1217-1225, doi:10.5194/acp-11-12172011, 2011.

Müller, D., Mattis, I., Ansmann, A., Wandinger, U., Ritter, C., and Kaiser, D.: Multiwavelength Raman lidar observations of particle growth during long-range transport of forest-fire smoke in the free troposphere, Geophys. Res. Lett., 34, L05803, doi:10.1029/2006GL027936, 2007. 
Müller, T., Laborde, M., Kassell, G., and Wiedensohler, A.: Design and performance of a three-wavelength LED-based total scatter and backscatter integrating nephelometer, Atmos. Meas. Tech., 4, 1291-1303, doi:10.5194/amt-4-1291-2011, 2011.

O’Neill, N. T., Dubovik, O., and Eck, T. F.: A modified Ångstrom coefficient for the characterization of sub-micron aerosols, Appl. Opt., 40, 2368-2375, 2001a.

O’Neill, N. T., Eck, T. F., Holben, B. N., Smirnov, A., and Dubovik, O.: Bimodal size distribution influences on the variation of Angstrom derivatives in spectral and optical depth space, J. Geophys. Res., 106, 9787-9806, 2001 b.

Pohjola, M. A., Pirjola, L., Karppinen, A., Härkönen, J., Korhonen, H., Hussein, T., Ketzel, M., and Kukkonen, J.: Evaluation and modelling of the size fractionated aerosol particle number concentration measurements nearby a major road in Helsinki - Part I: Modelling results within the LIPIKA project, Atmos. Chem. Phys., 7, 4065-4080, doi:10.5194/acp-7-4065-2007, 2007.

Raut, J. C., Chazette, P., and Fortain, A.: Link between aerosol optical, microphysical and chemical measurements in an underground railway station in Paris, Atmos. Environ., 43, 860-868, 2009.

Reche, C., Querol, X., Alastuey, A., Viana, M., Pey, J., Moreno, T., Rodríguez, S., González, Y., Fernández-Camacho, R., de la Rosa, J., Dall'Osto, M., Prévôt, A. S. H., Hueglin, C., Harrison, R. M., and Quincey, P.: New considerations for PM, Black Carbon and particle number concentration for air quality monitoring across different European cities, Atmos. Chem. Phys., 11, 6207-6227, doi:10.5194/acp-11-6207-2011, 2011.

Russell, P. B., Bergstrom, R. W., Shinozuka, Y., Clarke, A. D., DeCarlo, P. F., Jimenez, J. L., Livingston, J. M., Redemann, J., Dubovik, O., and Strawa, A.: Absorption Angstrom Exponent in AERONET and related data as an indicator of aerosol composition, Atmos. Chem. Phys., 10, 1155-1169, doi:10.5194/acp-101155-2010, 2010.
Seinfeld, J. H. and Pandis, S. P.: Atmospheric Chemistry and Physics, 2nd edn., John Wiley, New York, USA, 1232 pp., 2006.

Subramanian, R., Roden, C. A., Boparai, P., and Bond, T. C.: Yellow beads and missing particles: trouble ahead for filterbased absorption measurements., Aerosol Sci. Tech., 41, 630-637, 2007.

Sun, H., Biedermann, L., and Bond, T. C.: Color of brown carbon: a model for ultraviolet and visible light absorption by organic carbon aerosol, Geophys. Res. Lett., 34, L17813, doi:10.1029/2007GL029797, 2007.

UNEP: Integrated Assessment of Black Carbon and Tropospheric Ozone, Summary for Decision Makers, United Nations Environment Program and World Meteorological Organization, UNEP/GC/26/INF/20, Nairobi, Kenya, 2011.

Yang, M., Howell, S. G., Zhuang, J., and Huebert, B. J.: Attribution of aerosol light absorption to black carbon, brown carbon, and dust in China - interpretations of atmospheric measurements during EAST-AIRE, Atmos. Chem. Phys., 9, 2035-2050, doi:10.5194/acp-9-2035-2009, 2009.

Virkkula, A.: Correction of the calibration of the 3-wavelength Particle Soot Absorption Photometer (3גPSAP), Aerosol Sci. Tech., 44, 706-712, 2010.

Virkkula, A., Ahlquist, N. C., Covert, D. S., Arnott, W. P., Sheridan, P. J., Quinn, P. K., and Coffman, D. J.: Modification, calibration and a field test of an instrument for measuring light absorption by particles, Aerosol Sci. Tech., 39, 68-83, 2005.

WHO: Health Aspects of Air Pollution with Particulate Matter, Ozone and Nitrogen Dioxide, Report on a WHO Working Group, Bonn, Germany, 13-15 January 2003, WHO, Regional Office for Europe, Copenhagen, 2003. 